\title{
Neogene paleogeography provides context for understanding the origin and spatial distribution of cryptic diversity in a widespread Balkan freshwater amphipod
}

\author{
Michał Grabowski ${ }^{\text {Corresp., }}{ }^{1}$, Tomasz Mamos ${ }^{1}$, Karolina Bącela-Spychalska ${ }^{1}{ }^{\text {， }}$ Tomasz Rewicz ${ }^{2}$, Remi A Wattier ${ }^{3}$ \\ 1 Department of Invertebrate Zoology and Hydrobiology, University of Lodz, Łódź, Poland \\ 2 Laboratory of Microscopic Imaging and Specialized Biological Techniques, University of Lodz, Lodz, Poland \\ 3 Laboratoire Biogéosciences, Université de Bourgogne Franche-Comté, UMR CNRS 6282, Dijon, France \\ Corresponding Author: Michał Grabowski \\ Email address: michalg@biol.uni.lodz.pl
}

Background. The Balkans are a major biodiversity and endemism hotspot, worldwide. Among the freshwater biota, amphipods are known for their high cryptic diversity. However, little is known about the temporal and paleogeographic aspects of their evolutionary history. We used paleogeography as a framework for understanding the onset of diversification in Gammarus roeselii: 1) we hypothesised that, given the high number of isolated waterbodies in the Balkans, the species is characterised by high level of cryptic diversity, even on a local scale; 2 ) the long geological history of the region might promote prePleistocene divergence between lineages; 3) given that $G$. roeselii thrives both in lakes and rivers, its evolutionary history could be linked to the Balkan Neogene paleolake system; 4) we inspected whether the Pleistocene decline of hydrological networks could have any impact on the diversification of $G$. roeselii.

Material and Methods. DNA was extracted from 136 individuals collected from 26 sites all over Balkans. All individuals were amplified for ca. $650 \mathrm{bp}$ long fragment of the mtDNA cytochrome oxidase subunit I (COI). After defining molecular operational taxonomic units (MOTU) based on COI, 50 individuals were amplified for ca. 900 bp long fragment of the nuclear 28S rDNA. Molecular diversity, divergence, differentiation and historical demography based on COI sequences were estimated for each MOTU. The relative frequency, geographic distribution and molecular divergence between COI haplotypes were presented as a median-joining network. COI was used also to reconstruct time-calibrated phylogeny with Bayesian inference. Probabilities of ancestors' occurrence in riverine or lacustrine habitats, as well their possible geographic locations, were estimated with the Bayesian method. A Neighbour Joining tree was constructed to illustrate the phylogenetic relationships between $28 \mathrm{~S}$ rDNA haplotypes.

Results. We revealed that $G$. roeselii includes at least 13 cryptic species or molecular operational taxonomic units (MOTUs), mostly of Miocene origin. A substantial Pleistocene diversification withinMOTUs was observed in several cases. We evidenced secondary contacts between very divergent MOTUs and introgression of nDNA. The Miocene ancestors could live in either lacustrine or riverine habitats yet their presumed geographic localisations overlapped with those of the Neogene lakes. Several extant riverine populations had Pleistocene lacustrine ancestors.

Discussion. Neogene divergence of lineages resulting in substantial cryptic diversity may be a common phenomenon in extant freshwater benthic crustaceans occupying areas that were not glaciated during 
the Pleistocene. Evolution of $G$. roeselii could be associated with gradual deterioration of the paleolakes. The within-MOTU diversification might be driven by fragmentation of river systems during the Pleistocene. Extant ancient lakes could serve as local microrefugia during that time. 
1 Neogene paleogeography provides context for understanding the origin and spatial 2 distribution of cryptic diversity in a widespread Balkan freshwater amphipod

3

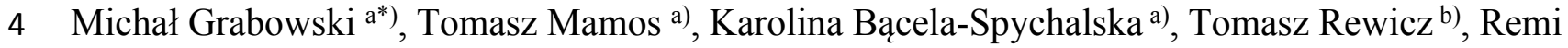
$5 \quad$ Wattier $\left.{ }^{c}\right)$

6

7 a) Department of Invertebrate Zoology and Hydrobiology, University of Lodz, 12/16 Banacha, 90$8237 \mathrm{Lodz}$, Poland

9 b) Laboratory of Microscopic Imaging and Specialized Biological Techniques, University of Lodz, Banacha 12/16, Łódź 90-237, Poland

c) Laboratoire Biogéosciences, Université de Bourgogne Franche-Comté, UMR CNRS 6282,

12 Équipe Écologie Évolutive, 6 boulevard Gabriel, 21000 Dijon, France

$13 *$ corresponding author, e-mail: michalg@biol.uni.lodz.pl 
25

26

\section{Abstract}

Background. The Balkans are a major biodiversity and endemism hotspot, worldwide. Among the freshwater biota, amphipods are known for their high cryptic diversity. However, little is known about the temporal and paleogeographic aspects of their evolutionary history. We used paleogeography as a framework for understanding the onset of diversification in Gammarus roeselii: 1) we hypothesised that, given the high number of isolated waterbodies in the Balkans, the species is characterised by high level of cryptic diversity, even on a local scale; 2) the long geological history of the region might promote pre-Pleistocene divergence between lineages; 3 ) given that $G$. roeselii thrives both in lakes and rivers, its evolutionary history could be linked to the Balkan Neogene paleolake system; 4) we inspected whether the Pleistocene decline of hydrological networks could have any impact on the diversification of G. roeselii.

Material and Methods. DNA was extracted from 136 individuals collected from 26 sites all over Balkans. All individuals were amplified for ca. $650 \mathrm{bp}$ long fragment of the mtDNA cytochrome oxidase subunit I (COI). After defining molecular operational taxonomic units (MOTU) based on COI, 50 individuals were amplified for ca. $900 \mathrm{bp}$ long fragment of the nuclear 28S rDNA. Molecular diversity, divergence, differentiation and historical demography based on COI sequences were estimated for each MOTU. The relative frequency, geographic distribution and molecular divergence between COI haplotypes were presented as a median-joining network. COI was used also to reconstruct time-calibrated phylogeny with Bayesian inference. Probabilities of ancestors' occurrence in riverine or lacustrine habitats, as well their possible geographic locations, were estimated with the Bayesian method. A Neighbour Joining tree was constructed to illustrate the phylogenetic relationships between $28 \mathrm{~S}$ rDNA haplotypes.

Results. We revealed that $G$. roeselii includes at least 13 cryptic species or molecular operational taxonomic units (MOTUs), mostly of Miocene origin. A substantial Pleistocene diversification within-MOTUs was observed in several cases. We evidenced secondary contacts between very divergent MOTUs and introgression of nDNA. The Miocene ancestors could live in either lacustrine or riverine habitats yet their presumed geographic localisations overlapped with those of the Neogene lakes. Several extant riverine populations had Pleistocene lacustrine ancestors. 
53 Discussion. Neogene divergence of lineages resulting in substantial cryptic diversity may be a 54 common phenomenon in extant freshwater benthic crustaceans occupying areas that were not 55 glaciated during the Pleistocene. Evolution of G. roeselii could be associated with gradual 56 deterioration of the paleolakes. The within-MOTU diversification might be driven by 57 fragmentation of river systems during the Pleistocene. Extant ancient lakes could serve as local 58 microrefugia during that time. 


\section{Introduction}

80

Due to its turbulent geological history over the last 30 million years, the Balkan Peninsula has been characterized by enormous and dynamic landscape change, resulting in great complexity. Both paleoenvironmental reconstructions and present day physiographic patterns are showing high habitat diversity and patchiness for both terrestrial and aquatic ecosystems (Popov et al., 2004). Movement of the African tectonic plate towards the north, and its collision with Eurasian plate in Neogene, at ca. 20 million years ago (Ma), caused the Tethys regression and uplift of the Hellenic and Dinaric Mountains, followed by abrupt paleoclimatic changes in Plio-Pleistocene that was intensified by Milankovitch climatic oscillations (Nisancioglu, 2010). As a result, the formation of hydrological networks throughout the Balkan Peninsula was considered a very complex process, with temporal existence of large lake systems, fragmentation of drainages, frequent river captures and progressing karstification. Thus, at present, the hydrological network is composed of several larger, and hundreds of smaller, drainages with relatively unstable watersheds (Economou et al., 2007). The isolation of habitat patches and emergence of new habitats in the course of the formation of the Balkan Peninsula provided a stimulus for speciation events, including: vicariance; peripatry; and parapatry (e.g. Griffiths, Kryštufek \& Reed, 2004; McInerney et al., 2014; Mamos et al., 2016). In consequence, the region is recognized as one of the most important present day hot-spots of biodiversity and endemism globally, and a model system for studies upon biogeography and the evolution of numerous organisms (Blondel \& Médail, 2009; Blondel et al., 2010; Poulakakis et al., 2015). Conventional faunistic and floristic studies show that the Balkans house ca. $35 \%$ of the Palearctic species and more than $6 \%$ of the world's freshwater species, with at least $43 \%$ of species being local endemics (Tierno de Figueroa et al., 2013). In addition, the area has been the focus of numerous late Pleistocene phylogeographic studies. Many of these studies highlight that it was probably a key glacial refugium for a number of animal and plant species during the last glacial period, and a source of post glacial recolonisation (Hewitt, 2000; Tzedakis, 2004; Pauls, Lumbsch, \& Haase, 2006). In addition, some studies also pointed out the presence of 
105 cryptic diversity in various biota (Mamos et al., 2014; Previšić et al., 2014; Sworobowicz et al., 106 2015). In several cases, divergent lineages at the molecular level(e.g. $>2 \%$ divergence for the 107 mtDNA COI gene) are recognized within one morphospecies (Bickford et al., 2007; Milankov et 108 al., 2008; Klobučar et al., 2013), while some studies documented cryptic diversity using DNA 109 barcoding, via delimiting Molecular Operation Taxonomic Units (MOTU) (Copilaş-Ciocianu \& 110 Petrusek, 2015; Sworobowicz et al., 2015), and others addressed the evolutionary history behind 111 the observed diversity patterns (Wysocka et al., 2013; 2014; Mamos et al., 2016). Several papers 112 point out that the lineage divergence, in at least some species inhabiting the Balkan Peninsula, 113 dates back to the Neogene (20.03-2.58 Ma) or to the early Pleistocene (2.58-0.78 Ma); a time114 span well before the Last Glacial Maximum (Parmakelis et al., 2006; Copilaş-Ciocianu \& Petrusek 115 2015). Particularly in the case of freshwater animals, pre-Pleistocene changes in watersheds and 116 isolation of drainages associated with mountain chain uplift have probably shaped the 117 phylogeography more profoundly than the Pleistocene glaciations and associated climatic shifts 118 (e.g. Verovnik, Sket \& Trontelj, 2005; Mamos et al., 2016). However, so far there have been 119 relatively few attempts to link the distribution patterns of extant aquatic taxa to particular 120 geological events in the Balkans (Veith, Kosuch \& Vences, 2003; Fromhage, Vences \& Veith 121 2004; Falniowski \& Szarowska 2011; Mamos et al., 2016). This is not surprising, given that the 122 hydrological system of the area has been restructured many times during the already mentioned 123 turbulent and ca. 30 My long paleogeographical history of the area, which makes the interpretation 124 of results quite a difficult task.

Gammaridean amphipods (Crustacea) are an ideal model group to study diversity and distribution patterns in freshwater systems. They are strictly aquatic with very limited abilities to disperse among isolated water basins via ectozoochory (e.g. Segerstråle, 1954, Rachalewski et al. 2013). Also, they are usually unable to survive periods of drought longer than a few days in any stage of their ontogeny (Väinölä et al., 2008, Bącela-Spychalska et al. 2013, Rachalewski et al., 2013). Amphipods play a key role in maintaining energy flow in freshwater ecosystems, decomposing organic matter (Graca et al., 2001; Piscart et al., 2009) and, with their great abundance, providing an important food source for fish (MacNeil, Dick \& Elwood, 1999; Padovani et al., 2012). Being quite sensitive to pollution, native species of Gammarus Fabricius, 1775 are used as standard organisms for ecotoxicology testing (e.g. Sroda \& Cossu-Leguille, 2011; Gerhardt, Bloor \& Mills, 2011). Substantial cryptic diversity has already been detected in several 
136 groups of freshwaters amphipods in water bodies such as: isolated spring systems in desert areas 137 (Witt, Threloff \& Hebert, 2006; Seidel, Lang \& Berg, 2009); ancient lakes (Wysocka et al., 2013, 138 Grabowski, Wysocka \& Mamos, 2016); and subterranean waters (Trontelj et al., 2009), but also 139 in numerous river systems throughout Europe (Weiss et al., 2014; Mamos et al., 2016). However, 140 most of the above papers did not aim to explain the evolutionary and geological history behind the 141 observed diversity. Such studies are still relatively scarce and usually limited to higher taxonomic 142 levels (Hou et al., 2011; Hou, Sket \& Li, 2013; McInerney et al., 2014; Wysocka et al., 2014). 143 Only very recently, the onset of diversification in two widespread freshwater morphospecies, 144 Gammarus balcanicus Schäferna, 1922 and Gammarus fossarum Koch, 1836, in Central and 145 Southern Europe was studied and interpreted in the context of regional geological history (Copilaş146 Ciocianu \& Petrusek, 2015; Copilaş-Ciocianu \& Petrusek, 2016, Mamos et al., 2016). All these 147 studies have stressed that the diversification of both species is very old and dates back to 148 early/middle Miocene (20-15 Ma), when the continentalisation of the area took place due to the 149 Paratethys regression.

Gammarus roeselii Gervais, 1835 is an epigean morphospecies, characterised by rather 151 high morphological polymorphism, commonly found in lakes and rivers of the western Balkan Peninsula (Karaman \& Pinkster, 1977a; own unpublished data). Only in historical times, the species has expanded its range to the rivers of Western and Central Europe, from France and Netherlands in the west, to Poland in the east (Grabowski, Jażdżewski \& Konopacka, 2007 and references therein). The species is characterised by relatively wide tolerance to various environmental factors and some resistance to pollution (Gergs, Schlag \& Rothhaupt, 2013). It is also easy to tell apart from other local morphospecies of Gammarus by the presence of large dorsal spines on the metasome part of the body, combined with rich setation of appendages (Karaman \& Pinkster 1977a). The morphospecies is also well defined in phylogenetic terms; being monophyletic relative to other species of Gammarus in Europe (Hou et al. 2011). The well-defined distribution of $G$. roeselii in a region with long and dynamic geology makes it a suitable model species for studying the role of past geological events in shaping its present molecular diversity. as a framework for understanding the onset of diversification in Gammarus roeselii. First, we 165 hypothesise that, taking into account the high number of isolated waterbodies on the Balkans, the 
166 species will be characterised by high levels of cryptic diversity; even at a relatively small 167 geographic scale. Second, given the long and turbulent geological history of the region, we 168 hypothesise that most of the diversification and speciation events precedes the Pleistocene Ice 169 Ages. Third, provided G. roeselii is able to thrive in both lakes and rivers, we hypothesise that its 170 evolutionary history may be linked to the Balkan Neogene paleolake system and its further 171 deterioration during the geological history of the region. Finally, we inspect whether the 172 Pleistocene decline of hydrological networks in the Balkans could have any impact on the 173 diversification of $G$. roeselii.

Material and Methods

\section{6 \\ Sampling and taxonomic identification}

177 A total of 348 sites located in springs, streams, rivers and lakes all over the Balkan Peninsula, including the Peloponnese (Fig. 1) were surveyed in the years 2006-2008, using semi-quantitative effort, based on a kick sampling method with a benthic hand-net (e.g. Jażdżewski, Konopacka \& Grabowski, 2004). All the collected material was sorted on-site and gammarids were immediately fixed in $96 \%$ ethanol. In the laboratory, animals were identified to species level using morphological characters described in available keys (e.g. Karaman \& Pinkster, 1977a; Karaman \& Pinkster, 1977b; Karaman \& Pinkster, 1987; Pinkster 1993). Gammarus roeselii was found at 26 sites (Table 1). All the material used in this study has been stored in the permanent collection of the Department of Invertebrate Zoology and Hydrobiology, University of Lodz, Poland.

Molecular procedures (DNA extraction, PCR amplification and sequencing)

188

189

190

191

192

193

Genomic DNA was extracted from pieces of muscle tissue obtained from 1 to 12 individuals from each site, making up a total of 136 individuals (Table 1). All individuals were processed, via PCR, to amplify a ca. $650 \mathrm{bp}$ fragment of the mtDNA cytochrome $\mathrm{C}$ oxidase subunit I (COI), using the primer pairs: LCO1490 and HCO2198 (Folmer et al., 1994); UCOIF and UCOIR (Costa et al., 2009); and a newly designed primer pair COIGrF (5'-GCTAGHGCCGTAGGYACATC) and COIGrR2 (5'- RAATARGTGYTGGTACAGAATAGG). Details about which primers were 
194 specifically used for each individual are provided in Table S1. After defining molecular 195 operational taxonomic units (MOTU) based on the COI marker (see results), a subset of 50 196 individuals representing all the defined MOTUs was also amplified to provide a ca. $900 \mathrm{bp}$ long 197 fragment of the 28S nrDNA using 28F and 28R primers (Hou, Fu \& Li, 2007). An aliquot of each 198 PCR product was used to check the specificity and yield by agarose gel electrophoresis. PCR 199 products were EXO-FastAP (Thermo Scientific) purified prior to sequencing by Macrogen Inc., 200 Korea, using BigDye terminator technology. All the details of the molecular procedures were as 201 described in Mamos et al. (2016).

Sequence data authentication, editing and alignment

204 205

206

207

208

209

210

211

212

213

21 215

216

217

218

219

220

221

All sequences were positively verified as Gammarus DNA via BLASTn searches against GenBank (Altschul et al., 1990). Geneious 6.1.4 (Biomatters 2013) was used for sequence editing, trimmed to either 530 nucleotides (COI) or 560-563 nucleotides (28S) and aligned using Geneious alignment algorithm. Haplotypes were identified for each marker with the DnaSP software (Librado \& Rozas, 2009). All single marker haplotypic sequences were deposited in GenBank (Accession numbers in Table 1). For COI, Kimura 2-parameter (K2p) distance was calculated (e.g. between all haplotypes, or within and among MOTUs) using MEGA 6.0 (Tamura et al., 2013). Standard error estimates were obtained by a bootstrap procedure (1000 replicates).

\section{Time-calibrated reconstruction of phylogeny}

The time-calibrated phylogeny was reconstructed using the Bayesian inference (BI) in BEAST 1.8.1 (Drummond et al., 2012). Two amphipod species Dikerogammarus villosus (Sovinsky 1894) (EF570297) and Pontogammarus robustoides (G.O. Sars, 1894) (JF965990) were used as outgroups for $G$. roeselii in the following analysis. Given that no molecular clock calibration based on gammarid fossil material is available, the calibration was performed applying three different schemes in parallel: 1) secondary calibration points; 2) standard rate of evolution; and 3) geological calibration points. The first scheme was based on the secondary calibration points from Hou et al. (2011). We constrained the node between Gammarus sp3 (JF965959) and Gammarus 
222 rambouseki S. Karaman 1931 (JF965946) to 15.5 Ma. The node between these two species and

223 our sequences of $G$. roeselii was constrained to $22 \mathrm{Ma}$. Dating constraints were set to normal 224 distributions with 10\% standard deviation. The second calibration scheme applied the "standard" 225 rate of the COI evolution as 0.0115 per site per My (Brower 1994). The third scheme was based 226 on two geological calibration points: (a) withdrawal of Moesian Sea and subsequent formation of 227 modern Danube river system; (b) origins of ancient Lake Baikal. The calibration points, as well as 228 the prior settings, were described in detail in Mamos et al. (2016). For the first calibrated point (a) 229 we used sequences of G. cf. balcanicus from the Southern Carpathians (KU056394) and the Balkan 230 Mountains (KU056256). The constraint was set to the time between the withdrawal of the Moesian 231 Sea at ca. 2.6 Ma and emergence of the modern Danube system at ca. 1.3 Ma, which connected 232 formerly-isolated rivers of the Southern Carpathians and the Balkan Mountains (Miklos \& Neppel, 233 2010; Mamos et al., 2016). For the second calibration point (b) we used the common ancestor of 234 Acanthogammarids from the ancient Lake Baikal. A permanent lake in the Baikal basin that 235 originated probably ca. $27 \mathrm{Ma}$, but the conditions in the lake were subsequently changing. Thus, 236 the lacustrine species flocks may be much younger than the lake itself (Mats et al., 2000). 237 According to Mats et al. (2011), the radiation of Acanthogammarids, represented here by 238 Acanthogammarus brevispinus Dorogostaisky, 1922 (AY926651), Ommatogammarus albinus 239 Dybowsky, 1874 (AY926686) and Eulimnogammarus viridulus Bazikalova, 1945 (AY926665), 240 started at c. 17 Ma. Thus, the constraints were designed to produce results centred on this value 241 but ranging back to the origins of the lake.

In all three calibration schemes the strict clock (vs relaxed lognormal and relaxed exponential), general time-reversible (GTR) model of evolution with gamma-distributed rate heterogeneity (G) and a proportion of invariable sites (I) model of evolution (vs all other models available in BEAST) as well as the Birth-Death speciation process (vs Yule) were set as priors, 246 following the Akaike information criterion (AIC) through the Markov chain Monte Carlo 247 (MCMC) method of moments estimator (Baele et al., 2013) in Tracer 1.6 (Rambaut et al., 2014). Four MCMC, each with $20 \mathrm{M}$ iterations, were run and sampled every 2000 iterations. The Effective Sampling Size (ESS) of each parameter was verified to be above 200 in Tracer 1.6 (Rambaut et al., 2014). Runs were combined with LogCombiner 1.8.1 (Drummond et al., 2012) with 25\% burnin, and the maximum clade credibility chronogram was annotated using TreeAnnotator 1.8.1

252 (Drummond et al., 2012). Since all the time-calibrated phylogeny reconstructions provided 
253 congruent results (Table S2) we have used the tree obtained from the first calibration scheme as a 254 proxy for following analysis of MOTU delimitation and Bayesian reconstruction of ancestral 255 states. Our interpretation of the obtained results in the context of local paleogeography follows the 256 established and commonly accepted intercalibrations of direct and stratigraphic dating provided 257 by Gradstein, Ogg \& Smith (2004) and by Piller, Harzhauser \& Mandic (2007), which were 258 summarised for the area by Hazhauser \& Mandic (2008).

259 In order to provide additional support for the BI topology we have also reconstructed a 260 phylogeny using the Maximum Likelihood approach (ML) in MEGA6 software (Tamura et al., 261 2013). The GTR $+\mathrm{G}+\mathrm{I}$ model of evolution was used with 1000 bootstrap replicates (Felsenstein, 262 1985).

Analysis of diversification rates

265 The history of diversification was explored using the lineage through time (LTT) plot generated 266 by using $1000 \mathrm{BI}$ trees in Tracer 1.6. In order to avoid artificial influence of coalescence on 267 terminal part of the plot we have used BI trees generated using the *BEAST algorithm (Heled \& 268 Drummond, 2010) in BEAST 1.8. Species delimited for the analysis were coded according to the 269 consensus MOTU's. The BI analysis was conducted using the same priors and MCMC settings as 270 in the first calibration scheme of the time calibrated reconstruction of phylogeny. To identify the 271 potential shifts in diversification we used Laser 2.3 package (Rabosky 2006) written in R (R Core 272 Team, 2012), a set of maximum likelihood-based methods for analyzing lineage diversification 273 rates. We estimated the fit of six speciation models (function fitdAICrc), assuming constant (pure

274 birth, birth death) and variable (Yule 2-rate, Yule 3-rate, exponential and logistic density 275 dependent) diversification rates, to the reconstructed BI phylogeny.

\section{Cryptic diversity - MOTU delimitation}

277 To explore the number of MOTUs that could represent putative cryptic species within the 278 morphospecies $G$. roeselii, we applied five different methods: i) a distance based Barcode Index 279 Number (BIN) System (Ratnasingham \& Hebert, 2013); ii) a distance-based barcode-gap approach 280 using the Automatic Barcode Gap Discovery (ABGD) software (Puillandre et al., 2012); iii) the 
281 tree-based, phylogenetic approach using the Bayesian implementation of the Poison Tree

282 Processor (bPTP) (Zhang et al., 2013) and iv and v) the tree-based general mixed Yule coalescent

283 (GMYC) model-based method (Pons et al., 2006), using either single and multiple threshold 284 models.

285

286

287

288

289

290

291

292

293

294

295

296

297

298

299

300

301

302

303

304

305

306

307

308

309

310

The BIN method is implemented as part of The Barcode of Life Data systems (BOLD; Ratnasingham \& Hebert, 2007). Newly submitted sequences are compared together as well as with sequences already available in BOLD. Sequences are clustered according to their molecular divergence using algorithms aiming at finding discontinuities between clusters. Each cluster is ascribed a globally unique and specific identifier (aka Barcode Index Number or BIN), already available or newly created if newly submitted sequences do not cluster with already known BINs. Each BIN is registered in BOLD.

The ABGD method is based upon pairwise distance measures. With this method the sequences are partitioned into groups (MOTUs), such that the distance between two sequences from two different groups will always be larger than a given threshold distance (i.e. barcode gap). We used primary partitions as a principal for group definition, as they are typically stable on a wider range of prior values, minimise the number of false positive (over-split species) and are usually close to the number of taxa described by taxonomists (Puillandre et al., 2012). The default value of 0.001 was used as the minimum intraspecific distance. As there is currently no consensus about which maximum intraspecific distance is reflecting delimitation of species, neither based on morphology (Costa et al., 2007, Weiss et al., 2014, or Katouzian et al., 2016) nor on reproductive barrier (Lagrue et al., 2014) we explored a set of values up to 0.01. The standard Kimura twoparameter (K2p) model correction was applied (Hebert et al., 2003).

The tree based bPTP method for species delimitation uses non-ultrametric phylogenies. The bPTP method incorporates the number of substitutions in the model of speciation and assumes that the probability that a substitution gives rise to a speciation event follows a Poisson distribution. The branch lengths of the input tree are supposed to be generated by two independent classes of the Poisson events, one corresponding to speciation and the other to coalescence. Additionally the bPTP adds Bayesian support values (BS) for the delimited species (Zhang et al., 2013). For the input tree we generated phylogeny using Bayesian inference in MrBayes 3.2 (Ronquist et al., 2012). Prior to tree construction, the out-group was removed from the alignment. The GTR+G+I 
311 model was selected using AICM method of moments estimator (Baele et al., 2013) in Tracer 1.6

312 (Rambaut et al., 2014). Four MCMC, each with 20 M iterations, were run and sampled every 2000 313 iterations. This was enough to obtain potential scale reduction factor values to equal 1 for all 314 parameters. Stable convergence was determined by inspecting the log likelihood values of the 315 chains and the split frequencies that reach, after 10 million generations, the value above 0.01 . The 316 consensus tree was constructed after removal of $25 \%$ burn-in phase. Analysis was performed on 317 the bPTP web server (available at: http://www.species.h-its.org/ptp/) with 500000 iterations of $318 \mathrm{MCMC}$ and $10 \%$ burn-in.

With the GMYC method, species boundaries are assessed based on sequences in a maximum likelihood framework by identifying the switch from intraspecific branching patterns (coalescent) to typical species branching patterns (Yule process) on a phylogenetic tree. First, a log-likelihood ratio test is performed to assess if the GMYC mixed models fit the observed data significantly better than the null model of a single coalescent species. Providing there is evidence for overlooked species inside the phylogenetic tree tested, two different GMYC approaches, one using the single threshold and the other one on multiple threshold model are used to estimate the boundary between intra- and interspecific branching patterns. Since the GMYC-method requires an ultrametric tree, we have used the already reconstructed Bayesian time calibrated phylogeny. The consensus tree was loaded into the $\mathrm{R}$ software package 'SPLITS' (Species Limits by Threshold Statistics) (Ezard, Fujisawa \& Barraclough, 2009) in R v3.1.0 (R Core Team, 2012) and analysed using the single and multiple threshold models. Presence of significant differences between the two models was tested using likelihood ratio test (LRT).

The program BayesTraits (Pagel, Meade \& Barker, 2004) was used to implement the MCMC Bayesian method, aiming at reconstructing ancestral states of a given trait along a phylogenetic tree. Two traits, habitat (river vs lake) and geographic coordinates (longitude and latitude) were explored. The BI maximum clade credibility chronogram was used as the input tree and the actual habitat type and geographic coordinates of its tips were used as input data for the actual state of the trait. For each ancestral node along the tree the results were reported as i) a chance (in 
340 percentage) for the ancestor to occur in a given habitat or ii) possible coordinates of the ancestor's

341 locality. In both cases the analysis was performed in two steps. Firstly, using the mentioned input 342 data, a distribution of models was estimated and saved into a file. Secondly, the input data with

343 file containing models distribution was used in the final analysis in which four independent, $10 \mathrm{M}$

344 iterations long, MCMC runs were performed and sampled every 1000 iterations, with 5\% burn-in.

345 Continuous and multistate reconstruction options with equal priors models, were used for

346 geographic coordinates and habitat, respectively. All runs in each analysis produced convergent

347 results that were combined and summarised (see Table S3 in Supporting Information). Mean and

348 standard deviations for the ancestral geographic coordinates were calculated in MS Excel.

Phylogenetic tree of $28 S$ haplotype and relationship with COI MOTUs

351 To display the relationships between the nuclear 28S rDNA haplotypes a phylogenetic Neighbor-

352 Joining (NJ) tree based p distance and node robustness being evaluated by 1000 bootstraps was 353 constructed using MEGA 6.0 (Tamura et al., 2013). To display relationship (i.e. discrepancy 354 between phylogenies) between nuclear and mitochondrial phylogenies COI MOTUs were plotted 355 on $28 \mathrm{~S} \mathrm{NJ}$ tree.

356

357

358

359

360

361

362

363

364

365

366

367

Within MOTU diversity, divergence, differentiation and historical demography: a Pleistocene tale

Molecular genetic diversity, divergence, differentiation and historical demography based on mtDNA COI sequences were, wherever possible, estimated for each MOTU. The relative frequency, geographic distribution and molecular divergence between COI haplotypes, were graphically presented as a median-joining (MJ) network (Bandelt, Forster \& Rohl, 1999) implemented in the program NETWORK 4.6.1.2 (http://www.fluxusengineering.com). Given the differences in substitution rates, we applied a weight of 1 for transition and 2 for transversions. The topology was obtained at the homoplasy level parameter default value $(e=0)$.

Diversity was assessed as the number of haplotypes $(\mathrm{k})$, haplotypic diversity $(h)$ and nucleotide diversity $(\pi)$ (Nei, 1987) with the DnaSP software (Librado \& Rozas, 2009). Molecular divergence was estimated as average Kimura 2 - parameters (K2p) distance between haplotypes 
368 using MEGA 6.0 (Tamura et al., 2013). In case of MOTUs present in more than one site (MOTUs

369 A, C, E, G and K) and given a minimum sampling size per site of 3 individuals, the differentiation 370 in haplotype frequencies was estimated as overall $\mathrm{F}_{\mathrm{ST}}$ through an Analysis of Molecular Variance 371 (AMOVA, Excoffier, Smouse \& Quattro, 1992) with 10000 permutations. In addition, pairwise 372 differentiation between locations was estimated through $\mathrm{F}_{\mathrm{ST}}$ (Weir \& Cockerham 1984) with 1023 373 permutations, and through Exact Tests of Sample Differentiation (ETSD, Raymond and Rousset 374 1995) with 30000 Markov steps. Historical demographic expansion within MOTUs at both the 375 scale of MOTUs and location was examined based on Tajima's D (Tajima 1989) and Fu's Fs (Fu, 376 1996) neutrality tests with 1000 replicates. All the above analyses were performed in Arlequin 377 3.5.1.3 (Excoffier \& Lischer, 2010).

\section{Results}

\section{Species geographic distribution and associated habitat}

381

382

383 384

We collected Gammarus roeselii from 26 sites on the Balkan Peninsula, including 18 riverine and 8 lacustrine sites belonging to 12 river basins draining to the Black, Adriatic, Ionian and Aegean seas as well as the isolated Prespa lake (Table 1, Fig. 1). The altitudinal range of the sites spans from the sea level to nearly 870 m.a.s.l. The longitudinal range of sites in which G. roeselii was found extended from the Adriatic/Ionian coast of the Balkan Peninsula $\left(15.7^{\circ} \mathrm{E}\right)$ on the west to the Struma river system $\left(24^{\circ} \mathrm{E}\right)$, and the latitudinal range extended from the Drava River $\left(46^{\circ} \mathrm{N}\right)$ down to the Corinthian Bay $\left(38.5^{\circ} \mathrm{N}\right)$. Despite extensive search, G. roeselii was not found neither in the eastern part of the Balkan Peninsula nor on the Peloponnese Peninsula. Other areas where we did not encounter presence of $G$. roeselii included central Serbia, Bosnia \& Herzegovina and coastal regions of Croatia.

\section{COI haplotypes: diversity, distribution and divergence}

Out of 136 individuals sequenced, a total of 74 haplotypes were identified (Accession numbers KP780673-KP780746) (Table 1). Only seven haplotypes were shared between a pair of locations (Table 1). Each of the remaining 67 haplotypes was specific to only one location (Table 1). 
396

397

398

399

400

401

402

403

404

405

406

407

408

409

410

411

412

413

414

415

416

417

418

419

420

421

422

423

Minimum, average and maximum K2p distance between haplotypes were, respectively, 0.0019 $(\mathrm{SE}=0.0017), 0.1463(\mathrm{SE}=0.0108)$ and $0.2405(\mathrm{SE}=0.0108)$. Such high average K2p distance suggests presence of cryptic diversity within the morphospecies (see also Table S4).

\section{Time calibrated reconstruction of phylogeny and analysis of diversification rate}

To infer the chronology of evolutionary events of diversification in G. roeselii, we performed a Bayesian time-calibrated reconstruction of phylogeny based on the COI marker. Both the Bayesian inferred (BI) chronogram and the Maximum Likelihood (ML) tree constructed in parallel had merely the same topology and high node supports (Fig. 2). The mean substitution rate associated with BI chronogram was 0.0113 in substitutions per site, per My, (SD 0.0016, 95\% HPD 0.00830.0144) for first calibration scheme and 0.0129 substitutions per site, per My (SD 0.0030, 95\% HPD 0.0077-0.0193) for third calibration scheme (Table S2).

The spatio-temporal pattern of lineage diversification within G. roeselii in the Balkan Peninsula appeared to be very complex (Fig. 2a, Table S1). The diversification started ca. $18 \mathrm{Ma}$ and produced a high number $(>10)$ of extant lineages. Spatial distribution of these lineages is heterogeneous, most of them are local endemics, two are relatively widespread and few occur in sympatry (Fig. 2b). The initial divergence (ca. $18 \mathrm{Ma}$ ) produced two groups of lineages - one spread over the northern part of the Balkan Peninsula, while the other one colonised southern part of this region. Each of the two groups is composed of a set of lineages that diverged before the beginning of Pleistocene glaciations, namely in Miocene (ca. 20.0-5.3 Ma) and Pliocene (ca. 5.32.6 Ma). The lineages through time plot (LTT, Fig. 3) shows that the accumulation of lineages was rather constant until Pleistocene. The analysis of diversification rate change through time showed that constant rate pure birth model and density-dependent speciation rate model with logistic variants fit the data best, with only a little difference between them $(\mathrm{dAIC}=0.21)$.

\section{Cryptic diversity/MOTU definition}

The thirteen MOTUs (A-M, Fig. 2) representing a set of potential cryptic species, we retained, are based on the combination of the information brought by i) five species delimitation methods (BINs, 
424 ABGD, bPTP, GMYC single threshold and GMYC multiple threshold model) and ii) the 425 divergence age on the BI chronogram (Fig. 2).

426

427

428

429

430

431

432

433

434

435

436

437

438

439

440

441

442

443

444

445

446

447

448

449

450

All the 173 sequences submitted to BOLD clustered into 27 BINs (details in Table S1).

The ABGD distance-based approach (barcode-gap analysis), resulted in eight primary partitions of the analysed COI sequences. Four of them were stable over a wide range of $\mathrm{P}$ values (0.001-0.10) and defined 12 MOTUs, being the same in each partition (Fig. 2).

The estimated number of MOTUs in bPTP ranged between 14 and 29, out of which 20 have Bayesian support values above 0.46. Eight of them are represented only by a single haplotype (Fig. 2).

In the GMYC, the null model of a single species was rejected in both, single and multiple threshold models (GMYC single LRT $<0.002$, GMYC multiple LRT $<0.0001$ ). Results of the chisquare test showed that there was no statistically significant difference between the two models $(\mathrm{LRT}=6.305, \mathrm{p}=0.39)$. Results of the single threshold analysis suggested the presence of 19 MOTUs (confidence interval: 12-30), out of which five consisted of single haplotypes. The results of the multiple threshold analysis suggested 24 MOTUs (confidence interval: 17-28), out of which seven consisted of single haplotypes (Fig. 2).

The 13 MOTUs retained, corresponded to the MOTUs identified by the ABGD method with the only exception that we decided to split one ABGD MOTU in two MOTUs (D+E). They diverged at ca. $4 \mathrm{Ma}$, already in the Pliocene, and the K2p distance between these MOTUs is ca. $6 \%$. Such a distance might have been associated with reproductive barrier observed in other Gammarus species (Lagrue et al. 2014) (Table S4, see Discussion).

\section{Chronology of divergence and geographical distribution of MOTUs}

The identified MOTUs formed two well defined primary clades. The first clade grouped MOTUs (A-H) occupying the northern and the central part of the Balkan Peninsula. The second one included MOTUs (I-M) present predominantly in the southern part of the peninsula. The clades appear to have diverged in the early Miocene (ca. $18 \mathrm{Ma}$ ) (Fig. 2a). 

A-G in the northern clade and I-J from K-M in the southern one. Next, within the northern clade, 453 at ca. $8 \mathrm{Ma}$, the group including MOTUs A-G separated into two subgroups A-E and F-G. The former, at ca. $7 \mathrm{Ma}$, gave rise to MOTU sets A-C and D-E. The MOTU C separated from the others 455 at ca. $4.5 \mathrm{Ma}$, while A and B diverged at ca. 4 Ma. MOTUs D and E separated at the same time. 456 Of the other subgroup, MOTUs F and G diverged at ca. 7 Ma. Within the southern clade, MOTUs 457 I and J diverged already at ca. $10 \mathrm{Ma}$. Then MOTU K separated from L-M at ca. $7 \mathrm{Ma}$ and, finally, 458 MOTU L diverged from $\mathrm{M}$ at ca. 3.3 Ma (Fig. 2a). seven sites, including rivers and lakes in the central Balkan Peninsula from the Aliakmonas drainage on the southwest, to the Vardar drainage on the north, and the Struma drainage on the east (Fig. 2b). MOTU A coexisted with MOTU D in the Vardar River drainage, the only place where MOTU D was found, and with MOTU E in the Struma River. The lacustrine populations of MOTU A inhabited Kastoria, Vegoritis and Petron lakes; all belonging to the Aliakmonas drainage. MOTU B was found only at one site in the southernmost part of the South Morava drainage, a major Danube tributary (Fig. 2b). MOTU C showed the northernmost distribution, being present only in rivers of the Danube drainage system (Black Sea basin), on the Pannonian Basin. MOTU E was another widely distributed lineage, found in the central part of the Balkan Peninsula. Interestingly, it was always found in sympatry with other MOTUs - with A in the Struma River, with G in the Shkumbin River, and with J in the upper Devoll River (a tributary of the Seman River). MOTU G, present in six sites, was predominantly associated with the Drin River drainage, including also the Ohrid and Prespa lakes, but also the nearby Shkumbin River, draining directly to the Adriatic Sea. MOTU H was found at only one isolated site in a small river on the Adriatic side of the Hellenic Mountains (Fig. 2b).

The MOTUs belonging to the southern group are spatially scattered and have very localised distributions (Fig. 2b). Each of them is restricted usually to only one waterbody or drainage area.

477 For example, the highly divergent MOTU I occupies the southernmost locality. It was found only 478 in the Trichonis Lake, on the Ionian side of the Hellenic Mountains. Its sister MOTU J was present only in a remote locality on the upper Devoll River, in the north-eastern outskirts of the Hellenic 480 Mountains. MOTU K was found in the Sperchios drainage on the Thessalian Plain and in the 
481 neighbouring Sofaditikos drainage in the Pelion Mountains. MOTU L was found in the Pinios

482 drainage, also in Thessaly. Interestingly, its sister MOTU M was found only in the remote Thyamis 483 drainage, on the Adriatic side of the Hellenic Mountains.

Reconstruction of the ancestral longitudes/latitudes and ancestral habitats of MRCAs

486

487

488

489

490

491

492

493

494

495

496

497

498

499

500

501

502

503

504

505

506

507

508

509

Reconstruction of the geographical origin of the most recent common ancestors (MRCAs) (Fig. 4a, Table S3) allowed to project the lineage diversification within G. roeselii on the present geography of the Balkan Peninsula and to interpret it in the paleogeographic context. The analysis showed that the early Miocene diversification of $G$. roeselii lineages might have started in the western part of the central Balkan Peninsula. From there, the northern clade could have spread to the neighbouring areas of the present Danube, Drin, Vardar, Shkumbin, Aliakmonas and Struma drainages; where it diversified throughout Miocene and Pliocene. The southern clade had colonised the southwestern parts of the Balkan Peninsula, diversifying in the Miocene and Pliocene, most probably on the eastern side of the Hellenic Mountains, before they effectively crossed the mountain chain and colonised now isolated watersheds. Finally, in the Pleistocene, a number of local diversification events occurred in MOTUs of both clades all over the species distribution on the Balkan Peninsula.

According to the reconstruction of the ancestral habitats of MRCAs (Fig. 2a), most of the Miocene ancestors could, with equal probability, have live both in lacustrine and riverine habitats. In several cases (MOTUs A, F and G), the extant riverine populations derived most probably directly from lacustrine ancestors. In case of MOTUs A and G the lacustrine ancestors of riverine populations were of Pleistocene age, while in the case of MOTU G, the presumed ancestor lived in the late Miocene.

Projection of the reconstructed longitudes and latitudes on paleomaps (Fig 4b-d) suggests that the early MRCA of extant G. roeselii MOTUs occurred in the area covered by the Neogene lake system occupying large parts of the western Balkan Peninsula. The reconstructed positions of the Miocene/Pliocene regional diversifications coincide with the major orogenic uplifts in the area, causing, among others, a decline of the lake systems and complete rearrangement of the local hydrological area. 
511

512 For each of the 13 MOTUs identified by the COI data, one to 18 individuals (50 in total) were 513 sequenced for the nuclear 28S marker, producing 23 haplotypes (N1-N23) (Table 1). The topology 514 of the Neighbor-Joining tree (Fig. 5) showing relationships between the 28S haplotypes was 515 partially concordant with the results derived from the mtDNA COI marker. For example, MOTUs 516 with high COI divergence (ca $>15 \% \mathrm{~K} 2 \mathrm{p}$ distance) were also divergent in the case of $28 \mathrm{~S}$. Only 517 MOTU E showed a peculiar pattern as its individuals, associated with three 28S haplotypes (N2, 518 N4 and N5), and belonged to two highly divergent clades of the 28S N-J tree (Fig. 5). Interestingly, 519 MOTU E was always sympatric (sites 11, 13, 20) with another distantly related MOTU G, J and 520 A, respectively. In two cases the individuals with COI haplotypes of MOTU E had a nuclear 521 haplotype either close (site 11, N2 vs N3 and N9) or even identical (site 13, N4 and N5) to the 522 nuclear haplotypes associated with the other MOTU present at the respective site.

523

524

525

526

527

528

529

530

531

532

533

534

535

536

537

COI: diversity and demography within MOTUs

Analysis of genetic diversity within all 13 defined MOTUs (Fig. 6), revealed a generally rather high level of haplotypic and nucleotide diversity as well as K2p distance from 0.002 to 0.029 (Table 2). This was also reflected by the fact that in numerous cases various species delimitation methods have subdivided the MOTUs we defined into smaller units. In all cases this intra-MOTU divergence is younger than $2.5 \mathrm{Ma}$. Such sub-MOTUs have very localized distributions, e.g. they are restricted to one lake (e.g. Prespa, Vegoritis/Petron) or one lake system (Kastoria, Ohrid). This suggests that the Pleistocene glaciations might have promoted diversification at the local scale. Only MOTU M showed a clear sign of demographic expansion (Table 2, Table S6). On the other side, results of AMOVA (Table 2), pairwise $\mathrm{F}_{\mathrm{ST}}$ and Exact Test of Sample Differentiation (ETSD) revealed significant differentiation between most populations of the same MOTUs inhabiting various locations (Table S7).

\section{Discussion}


539 Our findings point out the presence of 12 to 29 different MOTUs, depending on the delimitation 540 methods, that may represent plausible species. The higher estimates by GMYC and bPTP. which 541 are methods based on phylogeny and coalescence, may be associated with their general tendency 542 to overestimate the number of MOTUs in the presence of numerous highly divergent haplotypes, 543 or when MOTUs appear to be unevenly sampled; with some containing low, and others high, 544 within-MOTU genetic variability (Talavera, Dincă \& Vila, 2013; Zhang et al., 2013). On the other 545 hand, aggregating the haplotypes into BINs is based on a genetic distance threshold of $2.2 \%$ 546 (Ratnasingham \& Hebert, 2013) that may be too low for Gammarus (for details see Lagrue et al., 547 2014). Thus, it seems that the most conservative results of the ABGD analysis provide more 548 realistic estimates. A detailed study upon the taxonomy of Gammarus roeselii is beyond the scope 549 of our paper. In the only taxonomic review of European Gammarus made so far, and based 550 exclusively on morphological characters, Karaman \& Pinkster (1977a;b; 1987) synonymised nine 551 species and subspecies and recognised them as populations of G. roeselii. Our results are in clear 552 opposition to their conclusion and suggest that, in reality, G. roeselii is a conglomerate of several 553 locally endemic species. For example, our study revealed that MOTUs A and D were found in the 554 Treska River of the Vardar system, while MOTUs A and E were found in the Struma River. Then, 555 it is quite likely that at least some previously synonymised species, such as Gammarus vardarensis 556 (S. Karaman, 1929), originally described from the Vardar River system, and Gammarus strumicae 557 (G. Karaman, 1974), described from the Struma River system, correspond to some of these 558 MOTUs. This points that another revision of $G$. roeselii should be made in the future, 559 implementing the integrative taxonomy approach, which is the only reasonable option in the case 560 of diverse animal groups with conservative morphology or poorly defined morphological 561 variability (Pante, Schoelinck \& Puillandre, 2015). High cryptic diversity with numerous 562 divergent, locally endemic MOTUs representing possibly cryptic and/or yet undescribed species 563 within other European freshwater amphipods was already evidenced for the morphospecies $G$.

564 balcanicus, which is widely spread from the eastern Carpathians through the Balkan Peninsula and 565 to the eastern Alps (Mamos, 2015; Copilaş-Ciocianu \& Petrusek, 2016). Accordingly, a high level 566 of cryptic diversity was found in case of $G$. fossarum inhabiting Carpathians, Balkans, Alps and 567 other upland areas in Europe (Westram et al., 2011; Weiss et al., 2014; Copilaş-Ciocianu \& 568 Petrusek, 2016). 
Mountainous areas with steep elevational gradients, such as the Balkan Peninsula, have often

570 been reported as local endemism and diversity hotspots of biota (Hou, Li \& Li, 2014; Luebert \& 571 Muller, 2015; Zhou et al., 2015; Katouzian et al., 2016). In southern Europe it was often a result 572 of speciation by isolation in consequence of severe alterations and fragmentations of habitats 573 during Pleistocene climatic oscillations (Hewitt, 2004; Salicini, Ibanez, \& Juste, 2013; Goncalves 574 et al., 2015). However, the presence of pre-Pleistocene lineages within conventionally recognised 575 morphospecies was reported for several terrestrial and fewer freshwater taxa, including: reptiles; 576 amphibians; and fish, but also insects and molluscs (e.g. Albrecht et al., 2007; Marková et al., 577 2010; Falniowski et al., 2012; Garcia Munoz et al., 2014; Previšić et al., 2014; Pabijan et al., 578 2015).

Our study revealed that the level of genetic divergence between most of the Gammarus roeselii lineages in the Balkan Peninsula is too high to be attributed to climatic fluctuations in the

581 Pleistocene. Similarly, Mamos et al. (2016) as well as Copilaş-Ciocianu \& Petrusek (2016) found 582 that the divergence within G. balcanicus started some 15-20 Ma, in early/middle Miocene. 583 Copilaş-Ciocianu \& Petrusek, (2015) found that G. fossarum diversified in the south-western 584 Carpathians 10-17 Ma. A high cryptic diversity of pre-Pleistocene origin was also recently 585 discovered within the freshwater isopod, Asellus aquaticus (Linnaeus, 1758), widely distributed 586 in Europe including the Balkan Peninsula. The MOTUs of A. aquaticus diverged over Miocene 587 and a number of them are localised in various parts of the Balkan Peninsula (Verovnik et al., 2005; 588 Sworobowicz et al., 2015), which is similar to the spatial distribution pattern we have obtained for 589 G. roeselii.

The impact of Neogene and Quaternary paleogeography on the diversification of Gammarus 592 roeselii

593 Historical framework of cryptic diversity within the Balkan freshwater taxa has beenpoorly 594 studied, with a clear exception of taxa inhabiting ancient lakes, such as: the Ohrid; Prespa; or 595 Trichonis (Albrecht et al., 2008; Wysocka et al., 2013; 2014). This is probably a result of the 596 dynamic paleogeography and geology of the area, which may restrain a historical interpretation of 
597 phylogenetic relationships between MOTUs and their observed spatial distribution patterns, 598 making it an uneasy endeavour.

599 Our BI chronograms based on two different calibration schemes provided estimations of 600 mean COI substitution rates, in substitutions per site, per million years, which did not differ 601 substantially (0.0113; SD 0.0016 vs 0.0129 ; SD 0.0030). They were also quite close to the COI 602 mutation rate (0.0165; SD 0.0018) obtained for the cryptic lineages of G. balcanicus by Copilaş603 Ciocianu \& Petrusek, (2016) and to the rate (0.0115) routinely used for arthropods (Brower 1994). 604 Thus, we can assume that our estimation of divergence times were reasonable and reliable in 605 comparison to other studies. According to our results, the divergence of G. roeselii MOTUs took 606 place within similar time frame as obtained in the other studies (reported above) upon Gammarus. 607 The two main groups of MOTUs split at ca. $18 \mathrm{Ma}$ (early middle Miocene) in the Neogene, and 608 this continued their diversification to individual MOTUs until less than $1 \mathrm{Ma}$ (Pleistocene) in the 609 Quaternary. During this time frame, the region was already a part of continental Europe; 610 undergoing rapid changes of terrain due to the uplift of the Dinaric and Hellenic mountain chains. 611 This included high tectonic activity of the area and recurrent reorganisations of local hydrological 612 networks (Popov et al., 2004; Dumurdzanov, Serafimovski \& Burchfiel, 2005). In the case of other 613 gammarids (Copilaş-Ciocianu \& Petrusek, 2015; 2016; Mamos et al., 2016), we can assume that 614 such landscape changes driven by Alpine orogenesis had a profound impact on the diversification 615 of $G$. roeselii in the Balkans. A major feature of the Balkan landscape was large freshwater 616 lacustrine systems, well supported by sediment and fossil data, existing throughout the Neogene 617 and undergoing dynamic changes due to local orogenic movements (Harzhauser \& Mandic, 2008; 618 Krstić, Savić \& Gordana, 2012). Unfortunately, we could not unambiguously define the ancestral 619 habitats of Miocene common ancestors for the extant MOTUs; they could have lived in either 620 rivers or lakes. However, reconstruction of the geographical origin of the Miocene and Pliocene 621 ancestors suggests that they lived most probably in the areas occupied contemporarily by large 622 freshwater lakes (Popov et al., 2004; Harzhauser \& Mandic, 2008; Krstić, Savić \& Gordana, 2012). 623 This allows us to speculate that they could have been lacustrine organisms that diversified 624 gradually along with the regression of the lakes and formation of new hydrological networks. At least some of the extant ancient, or presumably ancient, Balkan lakes are probably relicts 626 of these paleolake systems (Albrecht \& Wilke, 2008). Populations of G. roeselii were found in 
627 several of them, such as: Ohrid; Prespa; Trichonis etc. (see Table 1, Fig 1). The lacustrine 628 populations showed various levels of divergence from their sister riverine counterparts, dating 629 from as early as ca. $10 \mathrm{Ma}$ (Miocene) to as late as ca. $1 \mathrm{Ma}$ (Pleistocene). In a couple of cases, 630 populations of both types shared the same or closely related haplotypes. Our results for the 631 ancestral habitat reconstruction suggest that for MOTUs A, F and G, the extant riverine 632 populations derived from lacustrine ancestors. For example, the closest relatives of haplotypes 633 found in rivers of Northern Greece (MOTU A) are those from the local lakes of Kastoria, Petron 634 and Vegoritis, which are connected to the Aliakmonas River system. Similarly, in MOTU G, 635 haplotypes from the Shkumbin and Drin rivers in Albania are most closely related to those from 636 the ancient lakes Ohrid and Prespa. Some individuals from the Ohrid Lake share haplotypes with 637 those from the River Drin. The lake drains to Drin and, possibly, was historically connected to the 638 nearby Shkumbin River. Interestingly, for haplotypes from the currently isolated Lake Prespa, they 639 form a sister clade to all the other haplotypes of MOTU G, from which they diverged 1.5 Ma. 640 Similar sister relationships are also known e.g. within the gastropod genus Radix inhabiting both 641 lakes (Albrecht et al., 2008). It is also known that Lake Ohrid and Prespa were at once part of the 642 large Dessarete lake system (Albrecht \& Wilke, 2008). The most recent studies of the lake 643 sediment cores indicate that Lake Ohrid is at least 2 My old (Jovanovska et al., 2015). The age of 644 Lake Prespa remains unknown but it may be at least as old (Karaman, 1971; Radoman, 1985). A 645 split of that clade may reflect a separation of the Dessarete lakes and a relict character of the 646 population inhabiting rivers derived from the Dessaretes. An interesting case is whether MOTU I 647 is endemic to the ancient Lake Trichonis. This lake harbours several endemic species of molluscs 648 and fish (Doadrio \& Carmona, 1998; Albrecht et al., 2009; Almada et al., 2009). Its exact age is 649 not known, yet it is hypothesized to originate in the Pliocene, at ca. 3.4-1.8 Ma, or in the early 650 Pleistocene (Economidis \& Miller, 1990; Khondkarian, Paramonova \& Shcherba, 2004). The 651 Pleistocene origin of MOTU I diversity in the lake is supported by our results (Figure S1, Table 652 S3). Yet it is worth noting that it diverged from its sister, riverine MOTU J, at ca. 10 Ma. Given 653 the presumably Pliocene/Pleistocene age of Lake Trichonis, and results of our ancestral state 654 analysis, we may assume that MOTU I could derive either from a riverine or lacustrine ancestor. 655 In fact, almost all the Miocene ancestors in our analysis had a rather equal chance to be either 656 lacustrine or riverine. This may suggest that multiple habitat switches are evident in the 657 evolutionary past of $G$. roeselii, and this points out the potential importance of lacustrine systems 
658 for their diversification history. Climate aridisation that had started in the Miocene and intensified 659 greatly during the Pleistocene glaciations led to a periodical depletion of the riverine network in 660 southern Europe, as seen in the present day genetic diversity of freshwater biota (Tzedakis, 2007; 661 Macklin, Lewin \& Woodward, 2012; Gonzalez, Pedraza-Lara, \& Doadrio, 2014). In such climatic 662 conditions, the lakes could serve as local microrefugia, working as sources for the recolonisation 663 of river systems, restored during more humid periods. That is particularly plausible for the 664 Pleistocene, when recurrent glaciations resulting in droughts intermingled with humid 665 interglacials. Indeed, our results indicate that the direct lacustrine ancestors of extant riverine 666 populations for MOTUs A and G are of Pleistocene age. Similar conclusions may be derived from 667 the results of the $\mathrm{F}_{\mathrm{ST}}$ and ETDS analyses showing significant differentiation between localities. 668 Also, the aggregation of haplotypes into BINs may provide support for the Pleistocene speciation 669 by an isolation process, as observed in other taxa (Salicini, Ibanez, \& Juste, 2013; Goncalves et 670 al., 2015). It seems also that at least some MOTUs are versatile in changing habitats. They are 671 present in both lakes and rivers, and we may also assume that changing between such habitats 672 played an important role in the evolutionary history of G. roeselii.

673

674 Evidence of potential introgression between currently divergent MOTUs

675 In several examples, we observed incongruence between phylogenies based on the nuclear (28S) 676 and mitochondrial (COI) markers. Similar conflict between nuclear and mitochondrial genetic 677 diversity patterns was evident for the Balkan cyprinid fish, suggesting an exchange of genes after 678 initial isolation (Marková et al., 2010). Nuclear haplotypes shared randomly among numerous 679 mitochondrial lineages were observed for A. aquaticus and interpreted as a result of incomplete 680 lineage sorting (Verovnik et al., 2005; Sworobowicz et al., 2015). However, in the case of $G$. 681 roeselii such interpretation is implausible. Two nuclear haplotypes were shared only between 682 MOTUs E and J, which were not direct relatives and diverged from each other ca. 18 Ma. A third 683 nuclear haplotype of MOTU E was a close relative of a haplotype from MOTU G; while, based on 684 the COI sequence, the two MOTUs belonged to different clades that had separated ca. 8 Ma ago. 685 Moreover such a situation was observed only in the localities where the MOTUs occurred in 686 sympatry; suggesting that the female harboring nuclear haplotypes of MOTU E were fertilised by 687 males from the other locally present MOTUs. According to Morando et al., (2004) such 
688 phylogenetic patterns indicate secondary contact, resulting in hybridisation and/or introgression. 689 It is hard to speculate what enabled such secondary contacts in the case of G. roeselii. MOTU E 690 emerged at ca. 3.5 Ma, already in the Pliocene, and is the most diversified and internally divergent 691 (five COI BINs) of all the defined MOTUs, and is also present in three distant localities. Thus, two 692 main scenarios would be possible. One would assume a much wider presence of the MOTU before 693 the Quaternary as well as an extinction event for much of the former distribution area due to 694 Pleistocene climate aridisation resulting in a depletion of the river systems. According to this 695 scenario, secondary contact with other MOTUs would be possible via recurrently changing 696 watersheds during contemporary climate oscillations. A second scenario would assume a possible 697 overland transport by birds. Such possibility was proved for freshwater amphipods living in lakes 698 and shallow lowland rivers occupied by waterfowl (e.g. Segerstråle, 1954, Rachalewski et al., 699 2013). However it cannot be excluded, we believe it is less probable given that MOTU E was 700 found exclusively in rivers in rather mountainous terrain.

701

702

Conclusions

703

In conclusion, our study evidences that an old Neogene divergence of lineages resulting in 704 substantial cryptic diversity may be a common phenomenon, if not a rule, in extant freshwater benthic crustaceans, such as gammarids, occupying areas that were not glaciated during the Pleistocene. Our study is among the first proposing a historical scenario behind the cryptic diversity observed in obligatory freshwater invertebrates. It highlights the role of Neogene lakes and development of associated hydrological networks in speciation mechanisms, and high level of local endemism, leading to intricate distribution patterns of particular lineages. Also, it points out that the ancient lakes of the Balkan Peninsula might have acted as local refugia during the drought periods, particularly in the Pleistocene. Finally, by evidencing the introgression events, we may suggest that $G$. roeselii is a complex of species at various levels of speciation.

\section{Acknowledgments}


715 The authors wish to acknowledge several colleagues providing great help and company during the 716 fieldwork: Janusz Hejduk, Radomir Jaskuła, Yannis Karaouzas, Piotr Spychalski, and Krešimir

717 Žganec. We would also like to express our greatest thanks to all the local people in Albania, 718 Bulgaria, FYR of Macedonia, Greece and Romania that have always treated us with enormous 719 hospitality and were always willing to help. Without their selfless assistance we would never be 720 able to succeed in gathering all the material or, in some cases, survive. A few additional samples 721 from Slovenia, Croatia and Serbia were provided courtesy of Prof. Dr. Boris Sket, University of 722 Ljubljana, Slovenia. We are also very grateful to Dr. Kenneth De Baets, the Academic Editor of 723 PeerJ, and to three anonymous reviewers, for their in-depth reviews and critical comments that 724 allowed us to improve the quality of our manuscript. Mr Jamie Bojko from the University of Leeds, 725 UK, kindly agreed to perform the language corrections. Finally, as music is an inevitable part of 726 human life, we would like to thank the young British music band London Grammar for their beautiful compositions that inspired us along during data analysis and writing this paper.

\section{References}

730

731

732

733

734

735

736

737

738

739

740

741

742

Albrecht C, Schultheis R, Kevrekidis T, Streit B, Wilke T. 2007. Invaders or endemics? Molecular phylogenetics, biogeography and systematics of Dreissena in the Balkans. Freshwater Biology 52: 1525-1536.

Albrecht C, Wilke T. 2008. Ancient lake Ohrid: Biodiversity and evolution. Hydrobiologia 615: 103-40.

Albrecht C, Wolff C, Glöer P, Wilke T. 2008. Concurrent evolution of ancient sister lakes and sister species: The freshwater gastropod genus Radix in lakes Ohrid and Prespa. Hydrobiologia 615: 157-167.

Albrecht C, Hauffe T, Schreiber K, Wilke T. 2009. Mollusc biodiversity and endemism in the putative ancient Lake Trichonis (Greece). Malacologia 51: 357-375.

Almada VC, Robalo JI, Levy A, Freyhof J, Bernardi G, Doadrio I. 2009. Phylogenetic analysis of Peri-Mediterranean blennies of the genus Salaria: Molecular insights on the colonization of freshwaters. Molecular Phylogenetics and Evolution 52: 424-431. 
743 Altschul SF, Gish W, Miller W, Myers EW, Lipman DJ. 1990. Basic Local Alignment Search 744 Tool. Journal of Molecular Biology 215: 403-410.

745 Bącela-Spychalska K, Grabowski M, Rewicz T, Konopacka A, Wattier R. 2013. The 'killer 746 shrimp' Dikerogammarus villosus (Crustacea, Amphipoda) invading Alpine Lakes: overland transport by recreational boats and scuba-diving gear as potential entry vectors? Aquatic

749 750 751

752 753

754

755

756

757

758

759

760

761

762

763

764

765

766

767

768

769

770

Conservation: Marine \& Freshwater Ecosystems 23:: 606-618.

Baele G, Li WLS, Drummond AJ, Suchard MA, Lemey P. 2013. Accurate model selection of relaxed molecular clocks in Bayesian phylogenetics. Molecular Biology and Evolution 30: 239-243.

Bandelt HJ, Forster P, Rohl A. 1999. Median-joining networks for inferring intraspecific phylogenies. Molecular Biology and Evolution 16: 37-48.

Bickford D, Lohman DJ, Sodhi NS, Ng PKL, Meier R,Winker K, Ingram KK, Das I. 2007. Cryptic species as a window on diversity and conservation. Trends in Ecology \& Evolution 22: 148155.

Biomatters Inc. 2013. Geneious version 6.1.4 created by Biomatters. Available from: URL http://www.geneious.com/

Blondel J, Médail F. 2009. Biodiversity and conservation. In: Woodward C. ed. The Physical Geography of the Mediterranean basin Oxford University Press, 604-638.

Blondel J, Aronson J, Bodiou J-Y, Boeuf G. 2010. The Mediterranean Region: Biology Diversity through Space and Time. Oxford: Oxford University Press.

Brower AVZ. 1994. Rapid morphological radiation and convergence among races of the butterfly Heliconius erato inferred from patterns of mitochondrial DNA Evolution. Proceedings of the National Academy of Sciences USA 91: 6491-6495.

Copilaş-Ciocianu D, Petrusek A. 2015. The southwestern Carpathians as an ancient centre of diversity of freshwater gammarid amphipods: insights from the Gammarus fossarum species complex. Molecular Ecology 24: 3980-3992.

Copilaş-Ciocianu D, Petrusek A. 2016. Phylogeography of a freshwater crustacean species complex reflects a long-gone archipelago. Journal of Biogeography DOI:10.1111/jbi.12853. 
771 Costa FO, deWaard JR, Boutillier J, Ratnasingham S, Dooh RT, Hajibabaei M, Hebert PDN. 2007.

772 Biological identifications through DNA barcodes: the case of the Crustacea. Canadian $773 \quad$ Journal of Fisheries and Aquatic Sciences 64: 272-295.

774 Costa FO, Henzler CM, Lunt DH, Whiteley NM, Rock J. 2009. Probing marine Gammarus 775 (Amphipoda) taxonomy with DNA barcodes. Systematics and Biodiversity 7: 365-379.

776 Doadrio I, Carmona JA. 1998. Genetic divergence in Greek populations of the genus Leuciscus and its evolutionary and biogeographical implications. Journal of Fish Biology 53: 591-613.

778

779

780

781

782

783

784

785

786

787

788

789

790

791

792

793

794

795

796

797

Drummond AJ, Suchard MA, Xie D, Rambaut A. 2012. Bayesian Phylogenetics with BEAUti and the BEAST 1.7. Molecular Biology and Evolution 29: 1969-1973.

Dumurdzanov N, Serafimovski T, Burchfiel BC. 2005. Cenozoic tectonics of Macedonia and its relation to the South Balkan extensional regime. Geosphere 1: 1-22.

Economidis PS, Miller PJ. 1990. Systematics of freshwater gobies from Greece (Teleostei, Gobiidae). Journal of Zoology 221: 125-170.

Economou AN, Giakoumi S, Vardakas L, Barbieri R, Stoumboudi M, Zogaris S. 2007. The freshwater ichthyofauna of Greece - an update based on a hydrographic basin survey. Mediterranean Marine Science 8: 91-166.

Excoffier L, Smouse PE, Quattro J M. 1992. Analysis of molecular variance inferred from metric distances among DNA haplotypes: application to human mitochondrial DNA restriction data. Genetics 131: 479-491.

Excoffier L, Lischer HEL. 2010. Arlequin suite ver 3.5: A new series of programs to perform population genetics analyses under Linux and Windows. Molecular Ecology Resources 10: $564-567$.

Ezard T, Fujisawa T, Barraclough TG. 2009. Splits: species' limits by threshold statistics. R package, version 3. Available from: URL https://r-forge.r-project.org/R/?group_id=333

Falniowski A, Szarowska M. 2011. Radiation and phylogeography in a spring snail Bythinella (Mollusca: Gastropoda: Rissooidea) in continental Greece. Annales Zoologici Fennici 48: 6790. 
798 Falniowski A, Szarowska M, Glöer P, Pešić V, Georgiev D, Horsák M, Sirbu I. 2012. Radiation 799 in Bythinella (Mollusca: Gastropoda: Rissooidea) in the Balkans. Folia Malacologica 20: 1$800 \quad 10$.

801 Felsenstein J. 1985. Confidence limits on phylogenies: an approach using the bootstrap. Evolution 802 39: 783-791.

803

804

805

806

807

808

809

810

811

812

813

814

815

816

817

818

819

820

821

822

823

824 825

Folmer O, Black M, Hoeh W, Lutz R, Vrijenhoek R. 1994. DNA primers for amplification of mitochondrial cytochrome c oxidase subunit I from diverse metazoan invertebrates. Molecular Marine Biology and Biotechnology 3: 294-299.

Fromhage L, Vences M, Veith M. 2004. Testing alternative vicariance scenarios in Western Mediterranean discoglossid frogs. Molecular Phylogenetics and Evolution 31: 308-322.

Fu YX. 1996. New statistical tests of neutrality for DNA samples from a population. Genetics 143: $557-570$.

Garcia Munoz JE, Garcia Raso JE, Rodriguez A, Cuesta J. 2014. Cryptic speciation of Greek populations of the freshwater shrimp genus Atyaephyra de Brito Capello, 1867 (Crustacea, Decapoda), evidence from mitochondrial DNA. Zootaxa 3790: 401-424.

Gergs R, Schlag L, Rothhaupt KO. 2013. Different ammonia tolerances may facilitate spatial coexistence of Gammarus roeselii and the strong invader Dikerogammarus villosus. Biological Invasions 15: 1783-1793.

Gerhardt A, Bloor M, Mills CL. 2011. Gammarus: Important taxon in freshwater and marine changing environments. International Journal of Zoology Article ID 524276.

Goncalves H, Maia-Carvalho B, Sousa-Neves T, Garcia-Paris M, Sequeira F, Ferrand N. MartinezSolano I. 2015. Multi locus phylogeography of the common midwife toad, Alytes obstetricans (Anura, Alytidae): Contrasting patterns of lineage diversification and genetic structure in the Iberian refugium. Molecular Phylogenetics and Evolution 93: 363-379.

Gonzalez EG, Pedraza-Lara C, Doadrio I. 2014. Genetic Diversity and Population History of the Endangered Killifish Aphanius baeticus. Journal of Heredity 105: 597-610.

Grabowski M, Jażdżewski K, Konopacka A. 2007. Alien Crustacea in Polish waters-Amphipoda. Aquatic Invasions 2: 25-38. 
826 Grabowski M, Wysocka A, Mamos T. 2016. Molecular species delimitation methods provide an 827 insight in taxonomy of the endemic gammarid species flock from the ancient Lake Ohrid. Zoological Journal of the Linnean Society DOI: 10.1093/zoolinnean/zlw025

829

830

831

832

833

834

835

836

837

838

839

840

841

842

843

844

845

846

Graca MAS, Cressa MO, Gessner MJ, Feio KA, Callies JA, Barrios C. 2001. Food quality, feeding preferences, survival and growth of shredders from temperate and tropical streams. Freshwater Biology 46: 947-957.

Gradstein, FM, Ogg JG, Smith AG. 2004. A geologic time scale. Cambridge University Press, Cambridge: I-XIX+1-589.

Griffiths HI, Kryštufek B, Reed JM. 2004. Balkan biodiversity: Pattern and process in the European hotspot. Dordrecht: Springer.

Harzhauser M, Mandic O. 2008. Neogene lake systems of Central and South-Eastern Europe: Faunal diversity, gradients and interrelations. Palaeogeography, Palaeoclimatology, Palaeoecology 260: 417-434.

Hebert PD, Cywinska A, Ball SL, deWaard JR. 2003. Biological identifications through DNA barcodes. Proceedings of the Royal Society B-Biological Sciences 270: 313-321.

Heled J, Drummond AJ. 2010. Bayesian inference of species trees from multilocus data. Molecular Biology and Evolution 27: 570-580.

Hewitt GM. 2000. The genetic legacy of the Quaternary ice ages. Nature 405: 907-913.

Hewitt GM. 2004. Genetic consequences of climatic oscillations in the Quaternary. Philosophical Transactions of the Royal Society B: Biological Sciences 1442: 183-195.

Hou Z, Fu J, Li S. 2007. A molecular phylogeny of the genus Gammarus (Crustacea: Amphipoda) based on mitochondrial and nuclear gene sequences. Molecular Phylogenetics and Evolution 45: 596-611.

Hou Z, Sket B, Fisěr C, Li S. 2011. Eocene habitat shift from saline to freshwater promoted Tethyan amphipod diversification. Proceedings of the National Academy of Sciences of the United States of America 108: 14533-14538.

Hou Z, Sket B, Li S. 2013. Phylogenetic analyses of Gammaridae crustacean reveal different diversification patterns among sister lineages in the Tethyan region. Cladistics 30: 352-364. 
854 Hou Z, Li J, Li S. 2014. Diversification of low dispersal crustaceans through mountain uplift: a 855 case study of Gammarus (Amphipoda: Gammaridae) with descriptions of four novel species. 856 Zoological Journal of the Linnean Society 170: 591-633.

857 Jażdżewski K, Konopacka A, Grabowski M. 2004. Recent drastic changes in the gammarid fauna 858 (Crustacea, Amphipoda) of the Vistula River deltaic system in Poland caused by alien 859

860 861 862 863

864 865

866

867

868

869

870

871

872

873 invaders. Diversity and Distribution 10: 81-87.

Jovanovska E, Cvetkoska A, Hauffe T, Levkov Z, Wagner B, Sulpizio R, Francke A, Albrecht C, Wilke T. 2015. Differential resilience of ancient sister lakes Ohrid and Prespa to environmental disturbances during the Late Pleistocene. Biogeosciences Discussions 12: 16049-16079.

Karaman M. 1971. Zoogeographische Verhältnisse des Prespa und Ochridsees. Izdanja, Institut de Pisciculture de la RS de Macédoine, Skopje 4: 1-21.

Karaman GS, Pinkster S. 1977a. Freshwater Gammarus species from Europe, North Africa and adjacent regions of Asia (Crustacea Amphipoda). Part II. Gammarus roeseli-group and related species. Bijdragen tot de Dierkunde 47: 165-196.

Karaman GS, Pinkster S. 1977b. Freshwater Gammarus species from Europe, North Africa and adjacent regions of Asia (Crustacea Amphipoda). Part I. Gammarus pulex-group and related species. Bijdragen tot de Dierkunde 47: 1-97.

Karaman GS, Pinkster S. 1987. Freshwater Gammarus species from Europe, North Africa and adjacent regions of Asia (Crustacea Amphipoda). Part III. Gammarus balcanicus-group and related species. Bijdragen tot de Dierkunde 57: 164-196.

Katouzian AR, Macher JN, Weiss M, Saboori A, Leese F, Weigand AM. 2016. Drastic underestimation of amphipod biodiversity in the endangered Irano-Anatolian and Caucasus biodiversity hotspots. Scientific Reports 6: e22507 DOI: 10.1038/srep22507.

Khondkarian SO, Paramonova NP, Shcherba IG. 2004. Map 10: Middle Late Pliocene (PiacentianGelasian, Late Romanian, Akchagilian). In: Popov SV, Rögl F, Rozanov AY, Steininger FF, Shcherba IG, Kovac M, eds. Lithological-paleogeographic maps of the Paratethys. Maps 110. Courier Forschungsinstitut Senckenberg, 250 S. V. Stuttgart: Nägele \& Obermiller, 3941. 
883 Klobučar GIV, Podnar M, Jelić M, Franjević D, Faller M, Štambuk A, Gottstein S, Simić V, 884 Maguire I. 2013. Role of the Dinaric Karst (western Balkans) in shaping the phylogeographic 885 886 structure of the threatened crayfish Austropotamobius torrentium. Freshwater Biology 58:

887

888

889

890

891

892

893

894

895

896

897

898

899

900

901

902

903

904

905

906

907

908

909

910

Krstić N, Savić L, Gordana J. 2012. The Neogene lakes on the Balkan land. Geoloski anali Balkanskoga poluostrva 73: 37-60.

Lagrue C, Wattier R, Galipaud M, Gauthey Z, Rullmann J-P, Dubreuil C, Rigaud T, Bollache L. 2014. Confrontation of cryptic diversity and mate discrimination within Gammarus pulex and Gammarus fossarum species complexes. Freshwater Biology 59: 2555-2570.

Librado P, Rozas J. 2009. DnaSP v5: A software for comprehensive analysis of DNA polymorphism data. Bioinformatics 25: 1451-1452.

Luebert F, Muller LA. 2015. Effects of mountain formation and uplift on biological diversity. Frontiers in Genetics 6: article 54.

Macklin MG, Lewin J, Woodward JC. 2012. The fluvial record of climate change. Philosophical Transactions of the Royal Society: A-Mathematical Physical and Engineering Sciences 370: $2143-2172$.

MacNeil C, Dick JTA, Elwood RW. 1999. The dynamics of predation on Gammarus spp. (Crustacea: Amphipoda). Biological Review 74: 375-395.

Mamos T. 2015 Phylogeography and cryptic diversity of Gammarus balcanicus Schäferna, 1922 in Europe. D. Phil. Thesis, University of Lodz.

Mamos T, Wattier R, Majda A, Sket B, Grabowski M. 2014. Morphological vs. molecular delineation of taxa across montane regions in Europe: the case study of Gammarus balcanicus Schäferna, 1922 (Crustacea: Amphipoda). Journal of Zoological Systematics and Evolutionary Research 52: 237-248.

Mamos T, Wattier R, Burzyński A, Grabowski M. 2016. The legacy of a vanished sea: a high level of diversification within a European freshwater amphipod species complex driven by $15 \mathrm{My}$ of Paratethys regression. Molecular Ecology 3: 795-810.

Marková S, Šanda R, Crivelli A, Shumka S, Wilson IF, Vukić J, Berrebi P, Kotlik P. 2010. Nuclear 
911

912

913

914 Mats VD, Khlystov OM, De Batist M, Ceramicola S, Lomonosova TK, Klimansky A. 2000.

915 Evolution of the Academician Ridge accommodation zone in the central part of the Baikal

916

917

918

919

920

921

922

923

924

925

926

927

928

929

930

931

932

933

934

935

936

937

938

and mitochondrial DNA sequence data reveal the evolutionary history of Barbus (Cyprinidae) in the ancient lake systems of the Balkans. Molecular Phylogenetics and Evolution 55: 488500.

Rift, from high-resolution reflection seismic profiling and geological field investigations. International Journal of Earth Sciences 89: 229-250.

Mats VD, Shecherbakov DY, Efimova I. 2011. Late Cretaceous-Cenozoic history of the Lake Baikal depression and formation of its unique biodiversity. Stratigraphy and Geological Correlation 19: 404-423.

McInerney CE, Maurice L, Robertson AL, Knight LR, Arnscheidt J, Venditti C, Dooley JG, Mathers T, Matthijs S, Eriksson K, Proudlove GS, Hanfling B. 2014. The ancient Britons: groundwater fauna survived extreme climate change over tens of millions of years across NW Europe. Molecular Ecology 23: 1153-1166.

Miklos D, Neppel F. 2010. Paleogeography of the Danube and its catchment. In: Mitja B, ed. Hydrological Processes of the Danube River Basin. Dordrecht Heidelberg London New York: Springer. 3: 79-124.

Milankov V, Stahls G, Stamenkovic J, Vujic A. 2008. Genetic diversity of populations of Merodon aureus and M. cinereus species complexes (Diptera, Syrphidae): integrative taxonomy and implications for conservation priorities on the Balkan Peninsula. Conservation Genetics 9: $1125-1137$.

Morando M, Avila LJ, Baker J, Sites JWJr. 2004. Phylogeny and phylogeography of the Liolaemus darwinii complex (Squamata: Liolaemidae): evidence for introgression and incomplete lineage sorting. Evolution 58: 842-861.

Nei M. 1987. Molecular evolutionary genetics. New York: Columbia University Press.

Nisancioglu KH. 2010. Plio-Pleistocene Glacial Cycles and Milankovitch Variability. In: Steele JH, Turekian KK, Thorpe SA, eds. Encyclopedia of Ocean Sciences. Academic Press, 504513. 
939 Pabijan M, Brown JL, Chan LM, Rakotondravony HA, Raselimanana AP, Yoder AD, Glaw F, 940 Vences M. 2015. Phylogeography of the arid-adapted Malagasy bullfrog, Laliostoma 941 labrosum, influenced by past connectivity and habitat stability. Molecular Phylogenetics and 942 Evolution 92: 11-24.

943 Padovani LN, Viñas MD, Sánchez F, Mianzan H. 2012. Amphipod-supported food web: Themisto 944 gaudichaudii, a key food resource for fishes in the southern Patagonian Shelf. Journal of Sea $945 \quad$ Research 67: 85-90.

946 Pagel M, Meade A, Barker D. 2004. Bayesian estimation of ancestral character states on 947 phylogenies. Systematic Biology 53: 673-684.

948 Pante E, Schoelinck C, Puillandre N. 2015. From integrative taxonomy to species description: one step beyond. Systematic Biology 64: 152-160.

950 Parmakelis A, Stathi I, Chatzaki M, Simaiakis S, Spanos L, Louis C, Mylonas M. 2006. Evolution 951 of Mesobuthus gibbosus (Brullé, 1832) (Scorpiones: Buthidae) in the northeastern Mediterranean region. Molecular Ecology 15: 2883-2894.

953

954

955

956

957

958

959

960

961

962

963

964

965

Pauls SU, Lumbsch HT, Haase P. 2006. Phylogeography of the montane caddisfly Drusus discolor: Evidence for multiple refugia and periglacial survival. Molecular Ecology 15: 21532169.

Piller WE, Harzhauser M, Mandic O. 2007. Miocene Central Paratethys stratigraphy — current status and future directions. Stratigraphy 4: 151-168.

Pinkster S. 1993. A revision of the genus Echinogammarus (Stebbing, 1899) with some notes on related genera. Memorie del Museo civico di storia naturale di Verona, IIa Serie A, Biologica, Sezione Scienze della vita 10: 1-185.

Piscart C, Genoel R, Doledec S, Chauvet E, Marmonier P. 2009. Effects of intense agricultural practices on heterotrophic processes in streams. Environmental Pollution 157: 1011-1018.

Pons J, Barraclough TG, Gomez-Zurita J, Cardoso A, Duran DP, Hazell S, Kamoun S, Sumlin WD, Vogler AP. 2006. Sequence-based species delimitation for the DNA taxonomy of undescribed insects. Systematic Biology 55: 595-609. 
966 Popov SV, Rögl F, Rozanov AY, Steininger FF, Shcherba IG, Kovac M. 2004. Lithological967 paleogeographic maps of Paratethys: 10 maps Late Eocene to Pliocene. Courier $968 \quad$ Forschungsinstitut Senckenberg 250: 1-46.

969 Poulakakis N, Kapli P, Lymberakis P, Trichas A, Vardinoyiannis K, Sfenthourakis S, Mylonas M. 970 2015. A review of phylogeographic analyses of animal taxa from the aegean and surrounding regions. Journal of Zoological Systematics and Evolutionary Research 53: 18-32.

972

973

974

975

976

977

978

979

980

981

982

983

984

985

986

987

988

989

990

991

992

Previšić A, Schnitzler J, Kučinić M, Graf W, Ibrahimi H, Kerovec M. Pauls SU. 2014. Microscale vicariance and diversification of Western Balkan caddisflies linked to karstification. Freshwater Science 33: 250-262.

Puillandre N, Lambert A, Brouillet S, Achaz G. 2012. ABGD, Automatic Barcode Gap Discovery for primary species delimitation. Molecular Ecology 21: 1864-1877.

R Core Group. 2012. R: a language and environment for statistical computing. R Foundation for Statistical Computing, Vienna, Austria. Available from: URL http://www.r-project.org/

Rabosky DL (2006) LASER: a maximum likelihood toolkit for detecting temporal shifts in diversification rates from molecular phylogenies. Evolutionary Bioinformatics, 2: 247-250.

Rachalewski M, Banha F, Grabowski M, Anastacio P. 2013. Ectozoochory as a possible vector enhancing the spread of an alien amphipod Crangonyx pseudogracilis. Hydrobiologia 717: 109-117.

Radoman P. 1985. Hydrobioidea, a superfamily of Prosobranchia (Gastropoda), II. Origin, zoogeography, evolution in the Balkans and Asia Minor. Belgrade: Monographs of the Institute of Zoology: 1-173.

Rambaut A, Suchard MA, Xie D, Drummond AJ. 2014. Tracer v1.6. Available from: URL http://beast.bio.ed.ac.uk/Tracer

Ratnasingham S, Hebert PDN. 2007. BOLD: The Barcode of Life Data System (www.barcodinglife.org). Molecular Ecology Notes 7: 355-364.

Ratnasingham S, Hebert PDN. 2013. A DNA-based registry for all animal species: The Barcode Index Number (BIN) system. PLoS ONE 8: e66213. 
993 Raymond M, Rousset F. 1995. Genepop (Version-1.2) — population-genetics software for exact 994 tests and ecumenicism. Journal of Heredity 86: 248-249.

995 Ronquist F, Teslenko M, van der Mark P, Ayres DL, Darling A, Höhna S, Larget B, Liu L, Suchard 996 MA, Huelsenbeck JP. 2012. MrBayes 3.2: efficient Bayesian phylogenetic inference and 997 998 999 model choice across a large model space. Systematic Biology 61: 539-542.

Salicini I, Ibanez C, Juste J, 2013. Deep differentiation between and within Mediterranean glacial refugia in a flying mammal, the Myotis nattereri bat complex. Journal of Biogeography 40: 1182-1193.

Seidel RA, Lang BK, Berg DJ. 2009. Phylogeographic analysis reveals multiple cryptic species of 1002 amphipods (Crustacea: Amphipoda) in Chihuahuan Desert springs. Biological Conservation 142: 2303-2313.

1004

1005

1006

1007

1008

1009

1010

1011

1012

1013

1014

1015

1016

1017

1018

Segerstråle SG. 1954. The freshwater amphipods Gammarus pulex (L.) and Gammarus lacustris (Sars) in Denmark and Fennoscandia - a contribution to the late and post-glacial immigration history of the aquatic fauna of northern Europe. Societas Scientiarum Fennica Commentationes Biologicae 15: 1-91.

Sroda S, Cossu-Leguille C. 2011. Effects of sublethal copper exposure on two gammarid species: which is the best competitor? Ecotoxicology 20: 264-273.

Sworobowicz L, Grabowski M, Mamos T, Burzyński A, Kilikowska A, Sell J, Wysocka A. 2015. Revisiting the phylogeography of Asellus aquaticus in Europe: Insights into cryptic diversity and spatiotemporal diversification. Freshwater Biology 60: 1824-1840.

Tajima F. 1989. Statistical method for testing the neutral mutation hypothesis by DNA polymorphism. Genetics 123: 585-595.

Talavera G, Dincă V, Vila R. 2013. Factors affecting species delimitations with the GMYC model: insights from a butterfly survey. Methods in Ecology and Evolution 4: 1101-1110.

Tamura K, Stecher G, Peterson D, Filipski A, Kumar S. 2013. MEGA6: Molecular Evolutionary Genetics Analysis Version 6.0. Molecular Biology and Evolution 30: 2725-2729. 
1019 Tierno de Figueroa JM, López-Rodríguez MJ, Fenoglio S, Sánchez-Castillo P, Fochetti R. 2013. 1020 Freshwater biodiversity in the rivers of the Mediterranean Basin. Hydrobiologia 719: 137$1021 \quad 186$.

1022 Trontelj P, Douady CJ, Fišer C, Gibert J, Gorički Š, Lefébure T, Sket B, Zakšek V. 2009. A 1023 molecular test for cryptic diversity in ground water: how large are the ranges of macro1024

1025 1026

1027

1028

1029

1030

1031

1032

1033

1034

1035

1036

1037

1038

1039

1040

1041

1042

1043

1044

1045 stygobionts? Freshwater Biology 54: 727-744.

Tzedakis PC. 2004. The Balkans as prime glacial refugial territory of European temperate trees. In: Griffith HI, Kryštufek B, Reed JM, eds. Balkan biodiversity - pattern and process in the European hotspot. Dordrecht: Kluwer Academic Publishers, 49-68.

Tzedakis PC. 2007. Seven ambiguities in the Mediterranean palaeoenvironmental narrative. Quaternary Science Reviews 26: 2042-2066.

Väinölä R, Witt JDS, Grabowski M, Bradbury JH, Jażdżewski K, Sket B. 2008. Global diversity of amphipods (Amphipoda; Crustacea) in freshwater. Hydrobiologia 595: 241-255.

Veith M, Kosuch J, Vences M. 2003. Climatic oscillations triggered post-Messinian speciation of western Palearctic brown frogs (Amphibia, Ranidae). Molecular Phylogenetics and Evolution 26: $310-327$.

Verovnik R, Sket B, Trontelj P. 2005. The colonization of Europe by the freshwater crustacean Asellus aquaticus (Crustacea: Isopoda) proceeded from ancient refugia and was directed by habitat connectivity. Molecular Ecology 14: 4355-4369.

Weir BS, Cockerham CC. 1984. Estimating F-Statistics for the analysis of population-structure. Evolution 38: 1358-1370.

Weiss M, Macher JN, Seefeldt MA, Leese F. 2014. Molecular evidence for further overlooked species within the Gammarus fossarum complex (Crustacea: Amphipoda). Hydrobiologia 721: 165-184.

Westram AM, Jokela J, Baumgartner C, Keller I. 2011. Spatial distribution of cryptic species diversity in European freshwater amphipods (Gammarus fossarum) as revealed by pyrosequencing. PLOS ONE 6: e23879. 
1046 Witt JD, Threloff DL, Hebert PD. 2006. DNA barcoding reveals extraordinary cryptic diversity in 1047 an amphipod genus: implications for desert spring conservation. Molecular Ecology 15: $1048 \quad 3073-3082$.

1049 Wysocka A, Grabowski M, Sworobowicz L, Burzyński A, Kilikowska A, Kostoski G, Sell J. 2013. 1050 A tale of time and depth: intralacustrine radiation in endemic Gammarus species flock from 1051 the ancient Lake Ohrid. Zoological Journal of the Linnean Society 167: 345-359.

Wysocka A, Grabowski M, Sworobowicz L, Mamos T, Burzyński A, Sell J. 2014. Origin of the Lake Ohrid gammarid species flock: ancient local phylogenetic lineage diversification. Journal of Biogeography 41: 1758-1768.

Zhang J, Kapli P, Pavlidis P, Stamatakis A. 2013. A general species delimitation method with applications to phylogenetic placements. Bioinformatics 29: 2869-2876.

Zhou T, Chen B-M, Liu G, Huang F-F, Liu J-G, Liao W-B, Wang Y-Y, Ren S-J, Chen C-Q, Peng S-L. 2015. Biodiversity of Jinggangshan Mountain: The importance of topography and geographical location in supporting higher biodiversity. PLOS ONE 10(3): Article Number:

1061 e0120208. 


\section{Table $\mathbf{1}$ (on next page)}

Sampling sites features and distribution of haplotypic diversity.

Table $1 . \mathrm{COI}=$ mtDNA cytochrome oxidase $\mathrm{I}$ and $28 \mathrm{~S}=$ nuclear $28 \mathrm{~S}$ ribosomal DNA. $\mathrm{N}=$ sampling size for each marker. MOTU = each haplotype is ascribed to one of the 13 identified MOTUs (A-M). Hap-Acc num(n) = haplotype name - Genbank Accession number ( number of individuals). 


\begin{tabular}{|c|c|c|c|c|c|c|c|c|c|c|c|}
\hline \multirow[t]{2}{*}{$\begin{array}{l}\mathrm{N} \\
{ }^{\circ}\end{array}$} & \multirow[t]{2}{*}{ Country } & \multirow[t]{2}{*}{ Site } & \multirow{2}{*}{ River basin } & \multirow[t]{2}{*}{$\begin{array}{l}\text { Sea } \\
\text { basin }\end{array}$} & \multirow[t]{2}{*}{ Coordinates (N, E) } & \multirow{2}{*}{$\begin{array}{l}\text { Altitude } \\
\text { (m) }\end{array}$} & \multicolumn{3}{|c|}{$\mathrm{COI}$} & \multicolumn{2}{|c|}{$28 \mathrm{~S}^{*}$} \\
\hline & & & & & & & $\mathrm{N}$ & MOTU & Hap-Acc num(n) & $\mathrm{N}$ & Hap-Acc num(n) \\
\hline 1 & SL & $\begin{array}{l}\text { Čreta, tributary of } \\
\text { Drava River }\end{array}$ & Danube & Black & $46.544167,15.614444$ & 360 & 3 & $\mathrm{C}$ & $\begin{array}{l}\text { C28-KP789695(3) } \\
* *\end{array}$ & - & \\
\hline 2 & SL & $\begin{array}{l}\text { Nova Vas, Drava } \\
\text { River }\end{array}$ & Danube & Black & $46.382111,15.939428$ & 215 & 2 & $\begin{array}{l}\mathrm{C} \\
\mathrm{C}\end{array}$ & $\begin{array}{l}\text { C25-KP789694(1) } \\
\text { C28-KP789695(1) }\end{array}$ & - & \\
\hline 3 & $\mathrm{CR}$ & $\begin{array}{l}\text { Varaždin, tributary } \\
\text { of Drava River }\end{array}$ & Danube & Black & $46.319815,16.359331$ & 170 & 1 & $\mathrm{C}$ & C23-KP789692(1) & - & \\
\hline 4 & $\mathrm{RO}$ & $\begin{array}{l}\text { Makovişte, Vicinic } \\
\text { River }\end{array}$ & Danube & Black & $44.942533,21.661000$ & 173 & 7 & $\mathrm{C}$ & C24-KP789693(7) & 2 & $\begin{array}{l}\text { N6-KP789752(1) } \\
\text { N7-KP789753(1) }\end{array}$ \\
\hline 5 & SE & $\begin{array}{l}\text { Ilince near Preševo, } \\
\text { tributary of Binačka } \\
\text { Morava River }\end{array}$ & Danube & Black & $42.354444,21.595278$ & 750 & 1 & B & C52-KP789715(1) & 1 & N23-KP789769(1) \\
\hline 6 & $\mathrm{AL}$ & Shkoder, Drin River & Drin & Adriatic & $42.024833,19.519133$ & 2 & 6 & $\begin{array}{c}\text { GG } \\
\text { G }\end{array}$ & $\begin{array}{l}\text { C32-KP789697(1) } \\
\text { C44-KP789708(3) } \\
\text { C45-KP789709(2) }\end{array}$ & - & \\
\hline 7 & $\mathrm{AL}$ & Lin, Ohrid Lake & Drin & Adriatic & $41.068617,20.645483$ & 682 & 5 & $\begin{array}{l}\mathrm{G} \\
\mathrm{G}\end{array}$ & $\begin{array}{l}\text { C31-KP789696(1) } \\
\text { C32-KP789697(4) }\end{array}$ & 1 & N3-KP789749(1) \\
\hline 8 & $\mathrm{AL}$ & $\begin{array}{l}\text { Gollomboç, Prespa } \\
\text { Lake }\end{array}$ & isolated/Drin*** & Adriatic & $40.861083,20.940450$ & 178 & 4 & $\begin{array}{l}G \\
G \\
G \\
G\end{array}$ & $\begin{array}{l}\text { C34-KP789698(1) } \\
\text { C35-KP789699(1) } \\
\text { C40-KP789704(1) } \\
\text { C41-KP789705(1) }\end{array}$ & - & \\
\hline 9 & MA & $\begin{array}{l}\text { Oteševo, Prespa } \\
\text { Lake }\end{array}$ & isolated/Drin*** & Adriatic & $40.969183,20.912217$ & 843 & 10 & $\begin{array}{l}\mathrm{G} \\
\mathrm{G}\end{array}$ & $\begin{array}{l}\text { C35-KP789699(3) } \\
\text { C38-KP789702(6) }\end{array}$ & 2 & $\begin{array}{l}\text { N3-KP789749(1) } \\
\text { N9-KP789755(1) }\end{array}$ \\
\hline
\end{tabular}




\begin{tabular}{|c|c|c|c|c|c|c|c|c|c|c|}
\hline & & & & & & & G & C42-KP789706(1) & & \\
\hline $10 \quad$ GR & $\begin{array}{l}\text { Microlimni, Micri } \\
\text { Prespa Lake }\end{array}$ & isolated/Drin*** & Adriatic & $40.745067,21.114217$ & 864 & 3 & $\begin{array}{l}G \\
G \\
G\end{array}$ & $\begin{array}{l}\text { C38-KP789702(1) } \\
\text { C39-KP789703(1) } \\
\text { C42-KP789706(1) }\end{array}$ & - & \\
\hline $11 \quad \mathrm{AL}$ & $\begin{array}{l}\text { Përrenjas, tributary } \\
\text { of Shkumbin River }\end{array}$ & Shkumbin & Adriatic & $41.074583,20.487933$ & 463 & 4 & $\begin{array}{l}\text { E } \\
G \\
G \\
G\end{array}$ & $\begin{array}{l}\text { C22-KP789691(1) } \\
\text { C36-KP789700(1) } \\
\text { C37-KP789701(1) } \\
\text { C43-KP789707(1) }\end{array}$ & 1 & N2-KP789748(1) \\
\hline $12 \quad \mathrm{AL}$ & $\begin{array}{l}\text { Orikum, Dukatit } \\
\text { River }\end{array}$ & Dukatit & Adriatic & $40.331967,19.477667$ & 9 & 4 & $\begin{array}{l}\mathrm{H} \\
\mathrm{H} \\
\mathrm{H} \\
\mathrm{H}\end{array}$ & $\begin{array}{l}\text { C59-KP789720(1) } \\
\text { C60-KP789721(1) } \\
\text { C61-KP789722(1) } \\
\text { C62-KP789723(1) }\end{array}$ & 4 & N1-KP789747(4) \\
\hline $\begin{array}{ll}13 & \mathrm{AL}\end{array}$ & $\begin{array}{l}\text { Zvezdë, Devoll } \\
\text { River }\end{array}$ & Seman & Adriatic & $40.708033,20.871200$ & 828 & 12 & $\begin{array}{l}E \\
E \\
E \\
E \\
J \\
J\end{array}$ & $\begin{array}{l}\text { C48-KP789711(1) } \\
\text { C49-KP789712(4) } \\
\text { C50-KP789713(1) } \\
\text { C51-KP789714(2) } \\
\text { C63-KP789724(1) } \\
\text { C64-KP789725(3) }\end{array}$ & 10 & $\begin{array}{l}\text { N4-KP789750(8) } \\
\text { N5-KP789751(2) }\end{array}$ \\
\hline 14 GR & $\begin{array}{l}\text { Soulopoulo, tributary } \\
\text { of Kalamas } \\
\text { (Thyamis) river }\end{array}$ & $\begin{array}{l}\text { Kalamas } \\
\text { (Thyamis) }\end{array}$ & Ionian & $39.718800,20.610083$ & 167 & 10 & $\begin{array}{l}\mathrm{M} \\
\mathrm{M} \\
\mathrm{M} \\
\mathrm{M} \\
\mathrm{M} \\
\mathrm{M} \\
\mathrm{M}\end{array}$ & $\begin{array}{l}\text { C84-KP789740(1) } \\
\text { C85-KP789741(1) } \\
\text { C86-KP789742(2) } \\
\text { C87-KP789743(1) } \\
\text { C88-KP789744(1) } \\
\text { C89-KP789745(1) } \\
\text { C90-KP789746(3) }\end{array}$ & 3 & $\begin{array}{l}\text { N11-KP789757(1) } \\
\text { N12-KP789758(1) }\end{array}$ \\
\hline $15 \quad$ GR & $\begin{array}{l}\text { Platanias, Trichonida } \\
\text { (Trichonis) Lake }\end{array}$ & Acheloos & Ionian & $38.596283,21.537317$ & 5 & 12 & $\begin{array}{l}\text { I } \\
\text { I } \\
\text { I } \\
\text { I } \\
\text { I }\end{array}$ & $\begin{array}{l}\text { C65-KP789726(1) } \\
\text { C66-KP789727(1) } \\
\text { C67-KP789728(1) } \\
\text { C68-KP789729(1) } \\
\text { C69-KP789730(1) }\end{array}$ & 5 & $\begin{array}{l}\text { N13-KP789759(2) } \\
\text { N14-KP789760(2) } \\
\text { N15-KP789761(1) }\end{array}$ \\
\hline
\end{tabular}




\begin{tabular}{|c|c|c|c|c|c|c|c|c|c|c|}
\hline & & & & & & & I & C70-KP789731(7) & & \\
\hline $16 \quad$ MA & $\begin{array}{l}\text { Canion Matka, } \\
\text { Treska River }\end{array}$ & Vardar (Axios) & Aegean & $41.963483,21.301367$ & 279 & 9 & $\begin{array}{l}\mathrm{A} \\
\mathrm{D}\end{array}$ & $\begin{array}{l}\text { C7-KP789679(7); } \\
\text { C21-KP789690(2) }\end{array}$ & 3 & N8-KP789754(3) \\
\hline 17 GR & Petres, Petron Lake & Aliakmonas & Aegean & $40.728267,21.681150$ & 585 & 9 & $\begin{array}{l}\mathrm{A} \\
\mathrm{A} \\
\mathrm{A}\end{array}$ & $\begin{array}{l}\text { C1-KP789673(6) } \\
\text { C2-KP789674(2) } \\
\text { C9-KP789680(1) }\end{array}$ & - & \\
\hline 18 GR & $\begin{array}{l}\text { Agios Panteleimon, } \\
\text { Vegoritis Lake }\end{array}$ & Aliakmonas & Aegean & $40.738600,21.754600$ & 290 & 9 & $\begin{array}{l}\mathrm{A} \\
\mathrm{A} \\
\mathrm{A} \\
\mathrm{A} \\
\mathrm{A}\end{array}$ & $\begin{array}{l}\text { C3-KP789675(1) } \\
\text { C4-KP789676(4) } \\
\text { C17-KP789687(1) } \\
\text { C18-KP789688(2) } \\
\text { C19-KP789689(1) }\end{array}$ & 1 & N10-KP789756(1) \\
\hline $19 \quad \mathrm{BU}$ & $\begin{array}{l}\text { Drangovo- } \\
\text { Marikostinovo, } \\
\text { Struma (Strymonas) } \\
\text { River }\end{array}$ & $\begin{array}{l}\text { Struma } \\
\text { (Strymonas) }\end{array}$ & Aegean & $41.413517,23.320050$ & 103 & 11 & $\begin{array}{l}\mathrm{A} \\
\mathrm{A} \\
\mathrm{A} \\
\mathrm{A} \\
\mathrm{A}\end{array}$ & $\begin{array}{l}\text { C10-KP789681(1) } \\
\text { C11-KP789682(1) } \\
\text { C12-KP789683(1) } \\
\text { C13-KP789684(7) } \\
\text { C16-KP789686(1) }\end{array}$ & - & \\
\hline 20 GR & $\begin{array}{l}\text { Petritsio, Struma } \\
\text { (Strymonas) River }\end{array}$ & $\begin{array}{l}\text { Struma } \\
\text { (Strymonas) }\end{array}$ & Aegean & $41.281817,23.332333$ & 60 & 7 & $\begin{array}{l}\text { A } \\
\text { A } \\
\text { E }\end{array}$ & $\begin{array}{l}\text { C13-KP789684(2) } \\
\text { C15-KP789685(1) } \\
\text { C46-KP789710(4) }\end{array}$ & 3 & N22-KP789768(3) \\
\hline 21 GR & $\begin{array}{l}\text { Kastoria, Kastoria } \\
\text { (Orestiada) Lake }\end{array}$ & Aliakmonas & Aegean & $40.514227,21.268950$ & 510 & 5 & $\begin{array}{l}\mathrm{A} \\
\mathrm{A}\end{array}$ & $\begin{array}{l}\text { C5-KP789677(1) } \\
\text { C6-KP789678(4) }\end{array}$ & - & \\
\hline $\begin{array}{ll}22 & \text { GR }\end{array}$ & $\begin{array}{l}\text { near Siatisti, } \\
\text { Aliakmonas River }\end{array}$ & Aliakmonas & Aegean & $40.288867,21.451133$ & 553 & 5 & A & C6-KP789678(5) & - & \\
\hline $23 \quad$ GR & $\begin{array}{l}\text { Aleksandria, } \\
\text { Aliakmonas River }\end{array}$ & Aliakmonas & Aegean & $40.583550,22.466033$ & 17 & 11 & $\begin{array}{l}F \\
F \\
F \\
F\end{array}$ & $\begin{array}{l}\text { C53-KP789716(1) } \\
\text { C54-KP789717(1) } \\
\text { C55-KP789718(1) } \\
\text { C56-KP789719(8) }\end{array}$ & 2 & N21-KP789767(2) \\
\hline
\end{tabular}




\begin{tabular}{|c|c|c|c|c|c|c|c|c|c|c|}
\hline $24 \quad$ GR & $\begin{array}{l}\text { Paliouri, Sperchios } \\
\text { River }\end{array}$ & Sperchios & Aegean & $38.943450,22.211767$ & 36 & 9 & $\begin{array}{l}\mathrm{K} \\
\mathrm{K}\end{array}$ & $\begin{array}{l}\text { C74-KP789734(4) } \\
\text { C76-KP789735(5) }\end{array}$ & 2 & $\begin{array}{l}\text { N16-KP789762(1) } \\
\text { N17-KP789763(1) }\end{array}$ \\
\hline $25 \quad$ GR & Omolio, Pinios River & Pinios & Aegean & $39.878333,22.584550$ & 35 & 9 & $\begin{array}{l}\mathrm{L} \\
\mathrm{L} \\
\mathrm{L} \\
\mathrm{L}\end{array}$ & $\begin{array}{l}\text { C78-KP789736(1) } \\
\text { C79-KP789737(1) } \\
\text { C80-KP789738(5) } \\
\text { C83-KP789739(2) }\end{array}$ & 3 & $\begin{array}{l}\text { N19-KP789765(2) } \\
\text { N20-KP789766(1) }\end{array}$ \\
\hline $\begin{array}{ll}26 & \text { GR }\end{array}$ & $\begin{array}{l}\text { Kedros, Sofaditikos } \\
\text { River }\end{array}$ & Pinios & Aegean & $39.176200,22.045983$ & 435 & 9 & $\begin{array}{l}\mathrm{K} \\
\mathrm{K}\end{array}$ & $\begin{array}{l}\text { C72-KP789732(8) } \\
\text { C73-KP789733(1) }\end{array}$ & 8 & $\begin{array}{l}\text { N17-KP789763(7) } \\
\text { N18-KP789764(1) }\end{array}$ \\
\hline
\end{tabular}

Country code: $\mathrm{SL}=$ Slovenia, $\mathrm{CR}=$ Croatia, $\mathrm{RO}=$ Romania, $\mathrm{SE}=$ Serbia, $\mathrm{AL}=$ Albania, $\mathrm{MA}=$ Macedonia, $\mathrm{BU}=\mathrm{Bulgaria}, \mathrm{GR}=\mathrm{Greece}$ * Notezthat sampling for $28 \mathrm{~S}$ was according to the MOTUs identified by COI, not geography. ** In bold - haplotypes shared by two sites. *** no connection via surface waters, but connected to the Ohrid Lake via karst underground channel. 


\section{Table 2 (on next page)}

Molecular genetic diversity, divergence, differentiation and historical demography based on mtDNA COI haplotypes in the MOTUs detected within Gammarus roeselii in the Balkans.

Table 2 . Locations = see Table 1 and Figure $1 \mathrm{~b}$ for details about locations. $\mathrm{N}=$ sample size.

Diversity: $\mathrm{k}=$ number of haplotypes. $h$ et $\pi=$ haplotype and nucleotide diversity, respectively. Divergence: $\mathrm{K} 2 \mathrm{p}=$ mean Kimura 2 parameters phenetic distance between haplotypes with a given MOTU. Differentiation $=$ overall $F_{S T}$ value. Demography: $D=$ Tajima's $D$ and Fs = Fu's Fs tests. 


\begin{tabular}{|c|c|c|c|c|c|c|c|c|c|}
\hline \multirow[t]{2}{*}{ MOTUs } & \multirow[t]{2}{*}{ Locations } & \multirow[t]{2}{*}{$\mathrm{N}$} & \multicolumn{3}{|c|}{ Diversity } & \multirow{2}{*}{$\begin{array}{c}\text { Divergence } \\
\mathrm{K} 2 \mathrm{p}\end{array}$} & \multirow{2}{*}{$\begin{array}{c}\text { Differentiation } \\
\mathrm{F}_{\mathrm{ST}}\end{array}$} & \multicolumn{2}{|c|}{ Demography } \\
\hline & & & $\mathrm{k}$ & $h$ & $\pi$ & & & $D$ & Fs \\
\hline $\mathbf{A}$ & $16^{a} 171819202122$ & 49 & 18 & 0.90 & 0.0153 & 0.016 & $0.79 * * *$ & $-0.08^{\mathrm{ns}}$ & $-0.69^{\mathrm{ns}}$ \\
\hline B & 5 & 1 & 1 & 0 & 0 & $\mathrm{n}-\mathrm{c}$ & - & 0 & $\mathrm{n}-\mathrm{c}$ \\
\hline $\mathbf{C}$ & 1234 & 13 & 4 & 0.65 & 0.0151 & 0.021 & $0.45 * * *$ & $0.78^{\mathrm{ns}}$ & $6.09^{\mathrm{ns}}$ \\
\hline D & 16 & 2 & 1 & 0 & 0 & $\mathrm{n}-\mathrm{c}$ & - & 0 & $n-c$ \\
\hline $\mathbf{E}$ & 111320 & 13 & 6 & 0.83 & 0.0189 & 0.029 & $0.68 * * *$ & $-0.98^{\mathrm{ns}}$ & $3.62^{\mathrm{ns}}$ \\
\hline $\mathbf{F}$ & 23 & 11 & 4 & 0.49 & 0.0033 & 0.006 & - & $-0.59^{\text {ns }}$ & $0.46^{\mathrm{ns}}$ \\
\hline $\mathbf{G}$ & 67891011 & 40 & 14 & 0.82 & 0.0112 & 0.016 & $0.76^{* * *}$ & $-0.32^{\mathrm{ns}}$ & $-0.56^{\mathrm{ns}}$ \\
\hline $\mathbf{H}$ & 12 & 4 & 4 & 1.00 & 0.0066 & 0.007 & - & $0.67^{\mathrm{ns}}$ & $-1.01^{\mathrm{ns}}$ \\
\hline $\mathbf{I}$ & 15 & 12 & 6 & 0.68 & 0.0036 & 0.006 & - & $-1.05^{\mathrm{ns}}$ & $-1.39^{\mathrm{ns}}$ \\
\hline $\mathbf{J}$ & 13 & 4 & 2 & 0.50 & 0.0009 & 0.002 & - & $-0.61^{\mathrm{ns}}$ & $0.17^{\mathrm{ns}}$ \\
\hline $\mathbf{K}$ & 2426 & 18 & 4 & 0.71 & 0.0028 & 0.004 & $0.79 * * *$ & $0.94^{\mathrm{ns}}$ & $0.89^{\text {ns }}$ \\
\hline $\mathbf{L}$ & 25 & 9 & 4 & 0.69 & 0.0132 & 0.024 & - & $-0.46^{\mathrm{ns}}$ & $3.65^{\mathrm{ns}}$ \\
\hline $\mathbf{M}$ & 14 & 10 & 7 & 0.91 & 0.0036 & 0.005 & - & $-1.40^{\mathrm{ns}}$ & $-3.42 *$ \\
\hline
\end{tabular}

$1 \mathrm{a}=$ sites in bold were part of the overall $\mathrm{F}_{\mathrm{ST}}$ estimate analysis. Some sites were discarded as their sampling size were too small. Significance

2 values $(p)$ of the parameters were evaluated with 10000 simulations: $\mathrm{ns}=$ not significant, $* \mathrm{P}<0.05 ; * * * \mathrm{P}<0.001$ 
Figure 1 (on next page)

Maps of the studied area and sampling sites.

Fig 1. Maps of a) the studied area and b) the 348 sampled sites (black dots denote the absence of Gammarus roeselii and sites numbered 1-26 the sites where the species was present. 
a peerJ

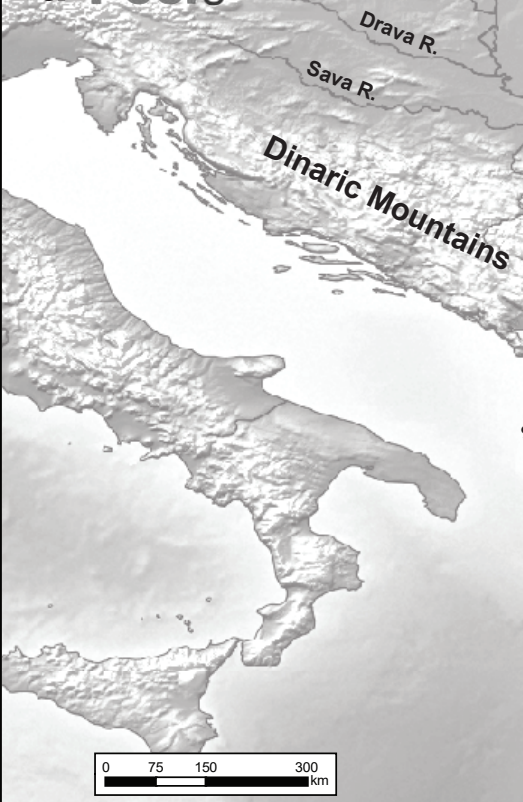

(1) $\frac{0}{3}$

Basin

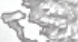

Manusempt to be re ewe is

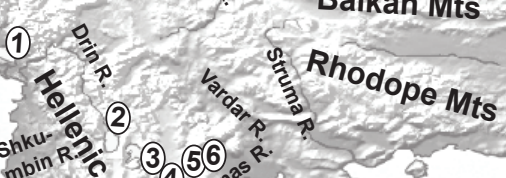
mbin R? $c$ (3) (5) 5$)^{2}$.

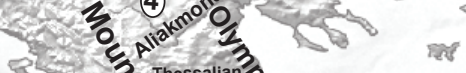
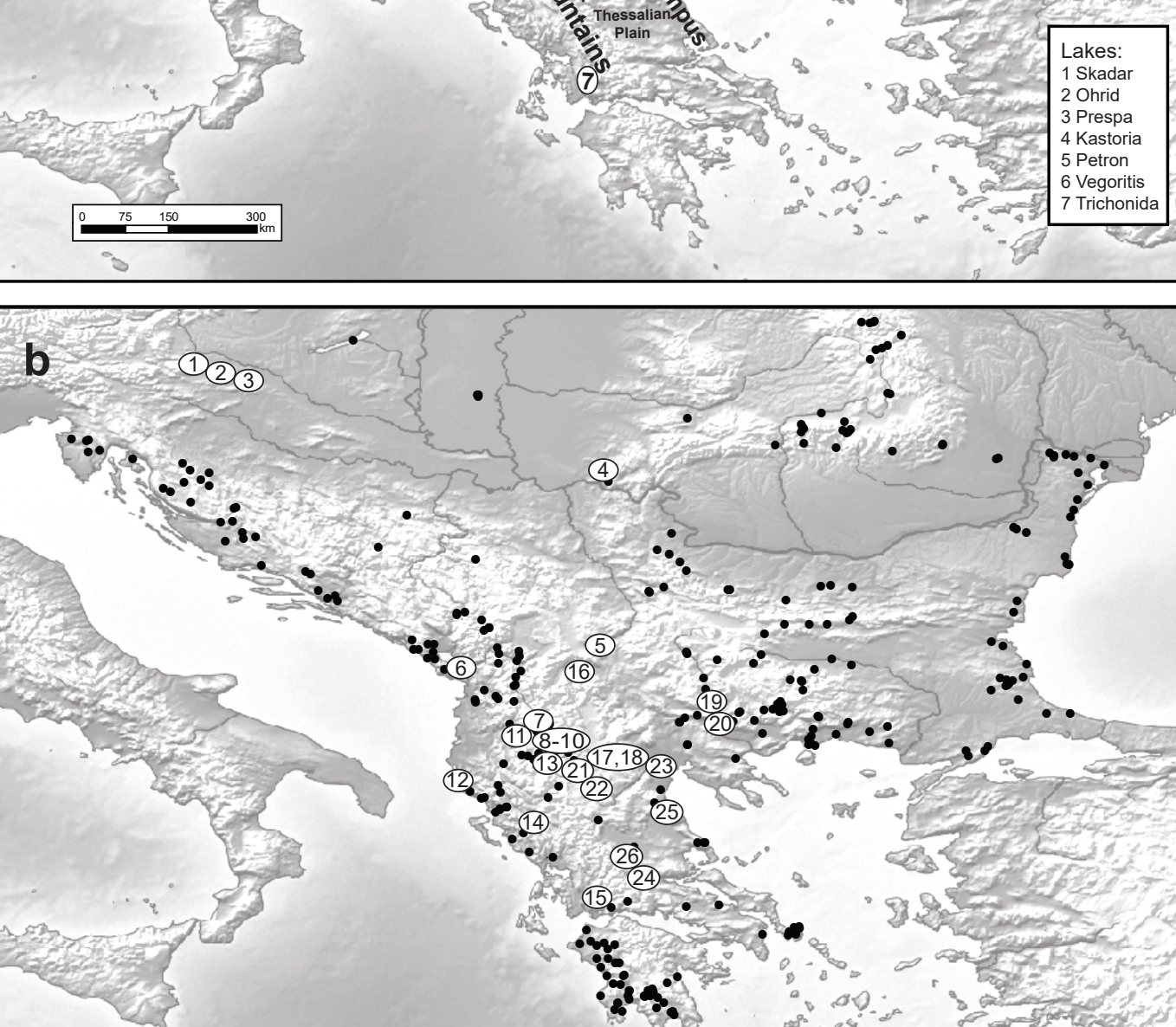

ह. 6 ?

(4)

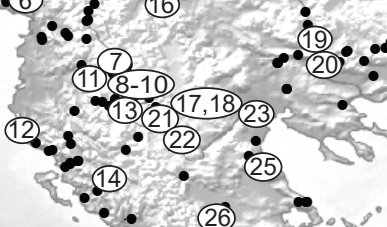

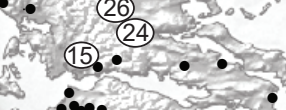

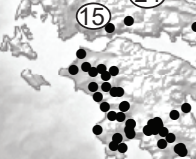

PeerJ reviewing PDF | (2016:06:11530:2:0:ACCEPTED 19 Jan 2017) 
Figure 2 (on next page)

Bayesian chronogram with MOTU designation.

Fig 2. a) Bayesian maximum clade credibility chronogram based on COI mtDNA including actual and ancestral state of habitat type (river vs lake), bars annotated on the right represents consensus MOTUs designation and results of the species delimitation methods (BINs, ABGD, bPTP, GMYC-single, GMYC-multiple). Values at nodes above branches are Bayesian posterior probabilities and bootstrap percentage, respectively before and after slash. Values below $50 \%$ denoted as -. Values at nodes below branches are split age in Ma. b) Geographic distribution of the MOTUs. 


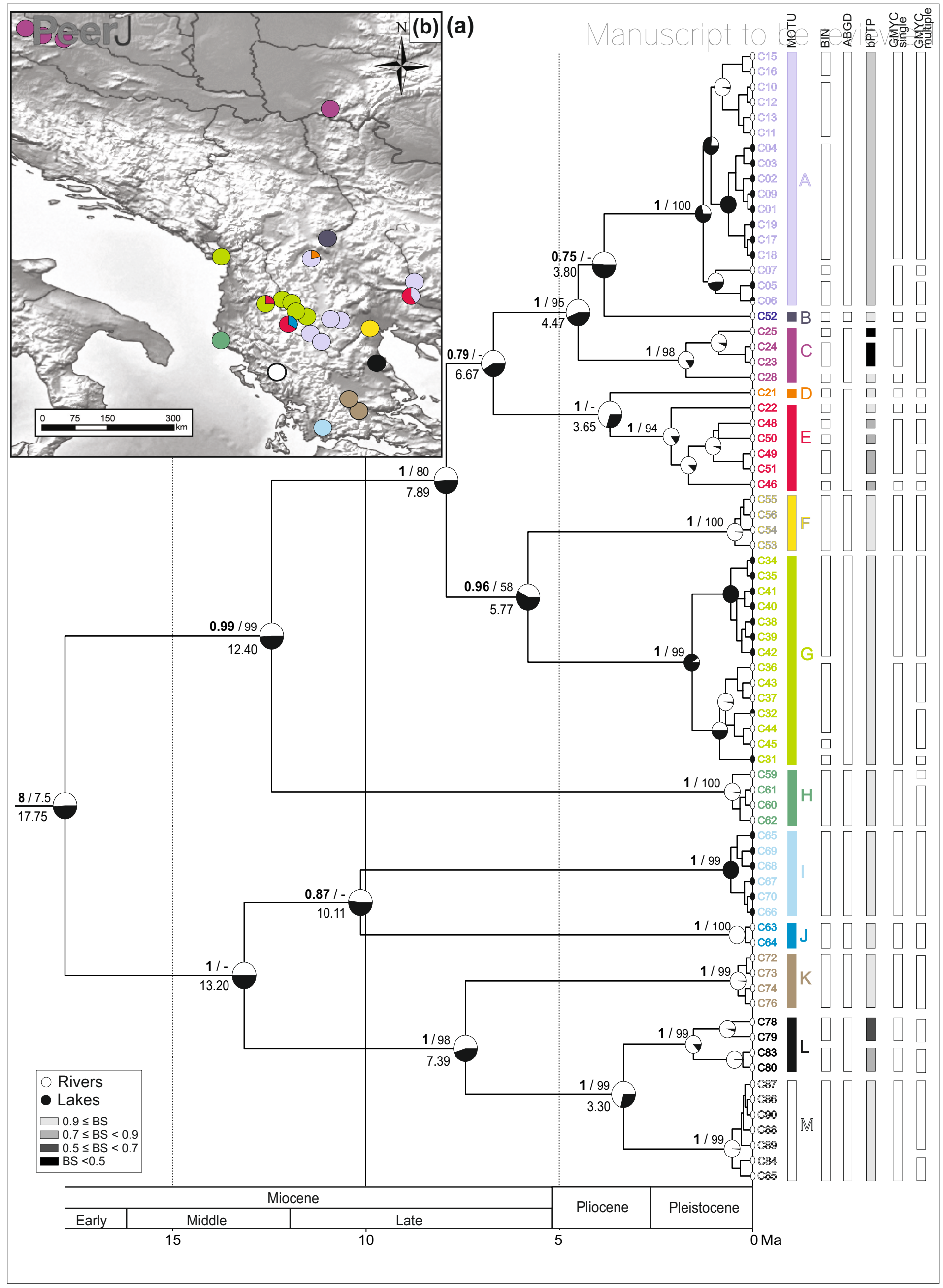


Figure 3 (on next page)

Lineages through time plot.

Fig 3. Haplotypes were collapsed to consensus MOTU's using *BEAST method. Grey lines represents 95\%HPD. 


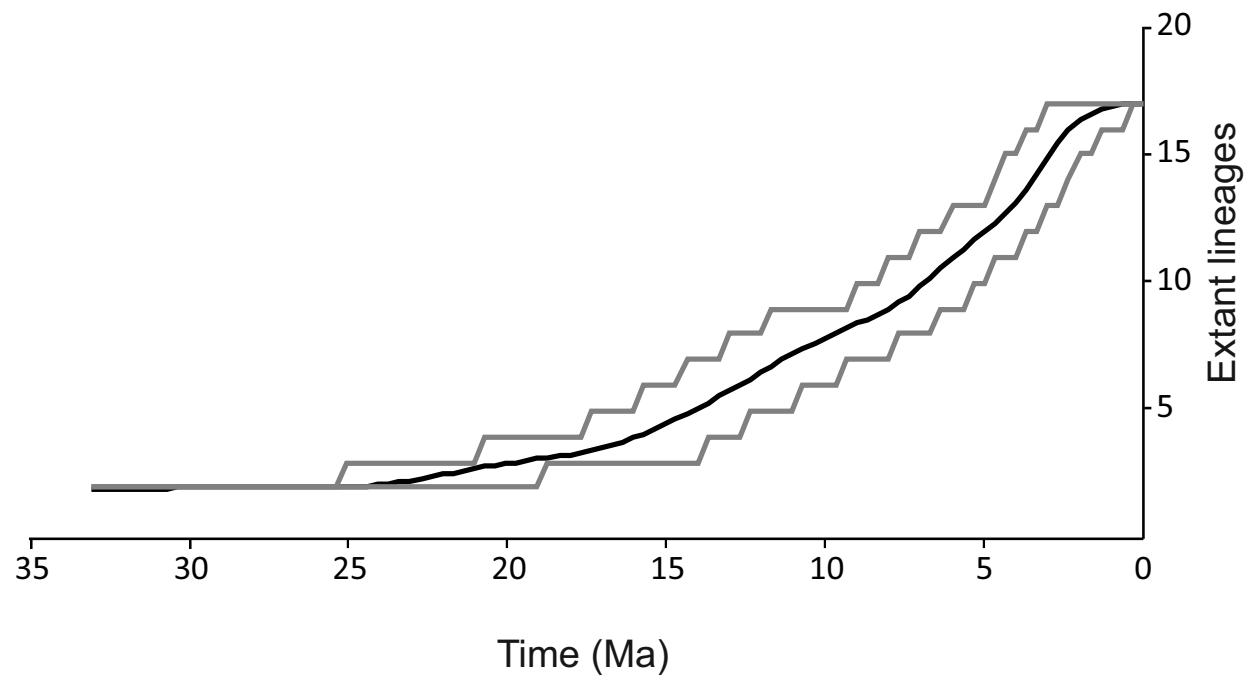


Figure 4(on next page)

Reconstruction of the putative geographic positions of ancestors.

Fig.4. Reconstruction of the putative geographic positions of ancestors based on the $\mathrm{COI}$ chronogram: a) position of the ancestors projected on the present-day geography of the studied area, b-d) positions of common ancestors (circle) and possible directions of colonization (arrows) projected on palaeomaps (redrawn after Popov et al. 2004) showing key geological events: b) early Middle Miocene 16-15 Ma. c) middle Middle Miocene 14-13 Ma, d) mid Late Miocene 7-6 Ma. 


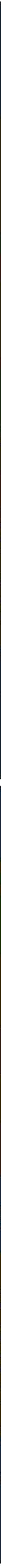


Figure $\mathbf{5}$ (on next page)

Phylogenetic Neighbour-Joining tree of nuclear 28S rDNA haplotypes.

Fig 5. Phylogenetic Neighbour-Joining tree based on uncorrected p-distance of nuclear $28 \mathrm{~S}$ rDNA haplotypes (N1-N23), ascribed to COI MOTUs (A-M). Color code for COI MOTUs is as in Fig. 2. Sampling sites are presented on Fig. 1 and in Table 1. Numbers in parentheses indicate sites where introgression between MOTUs was detected. 


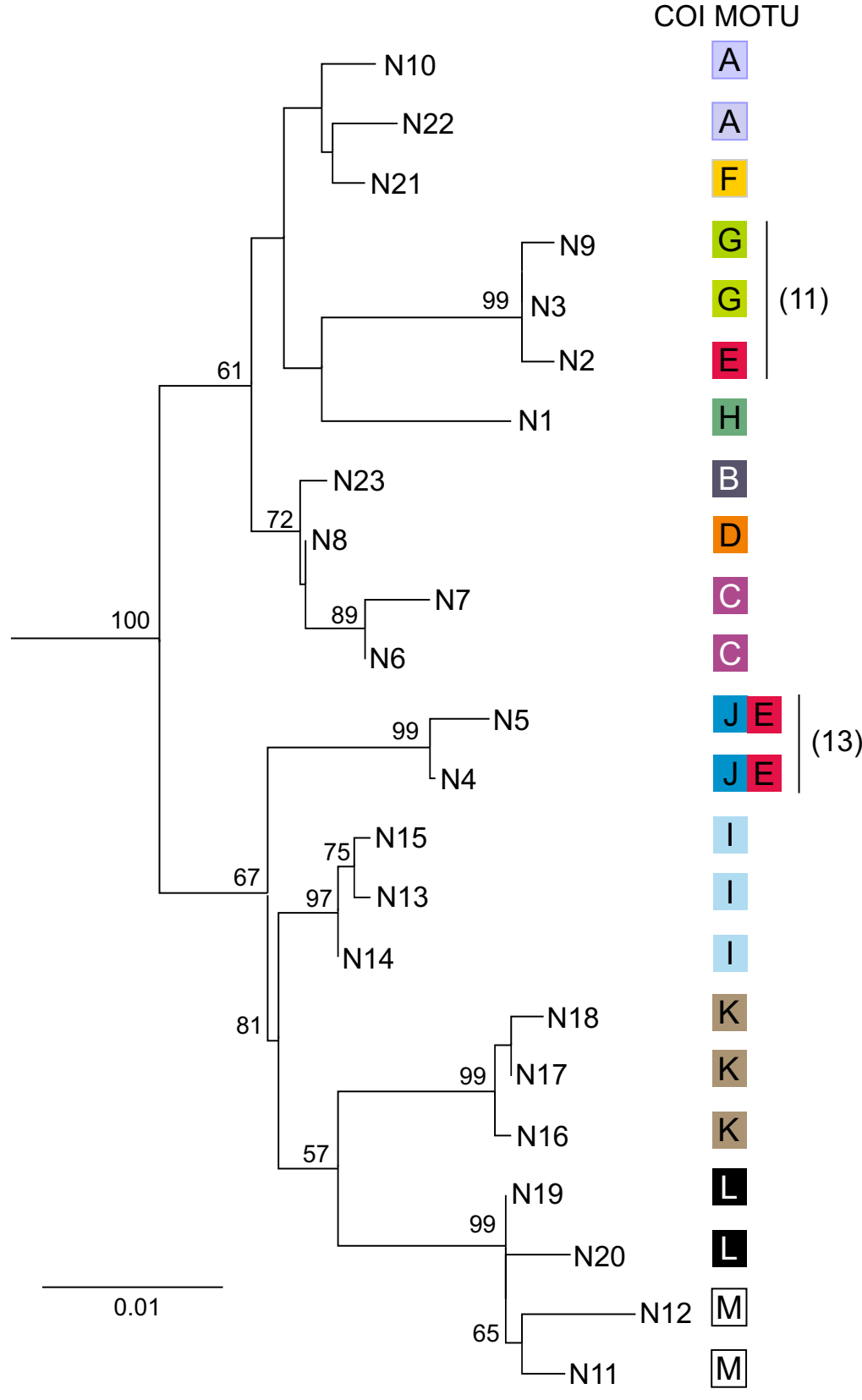


Figure 6 (on next page)

Median joining network for COI within the 13 defined pre-Pleistocene MOTUs (A-M).

Fig 6. Each circle represent one haplotype with the surface being proportional to the number of individuals sharing that haplotype. Minimum distance between two haplotype represents a one nucleotide difference distance. A dash indicates a substitution. Node indicates potential ancestral haplotype. Colors are referring to the 26 sampled sites (details in Table 1). 


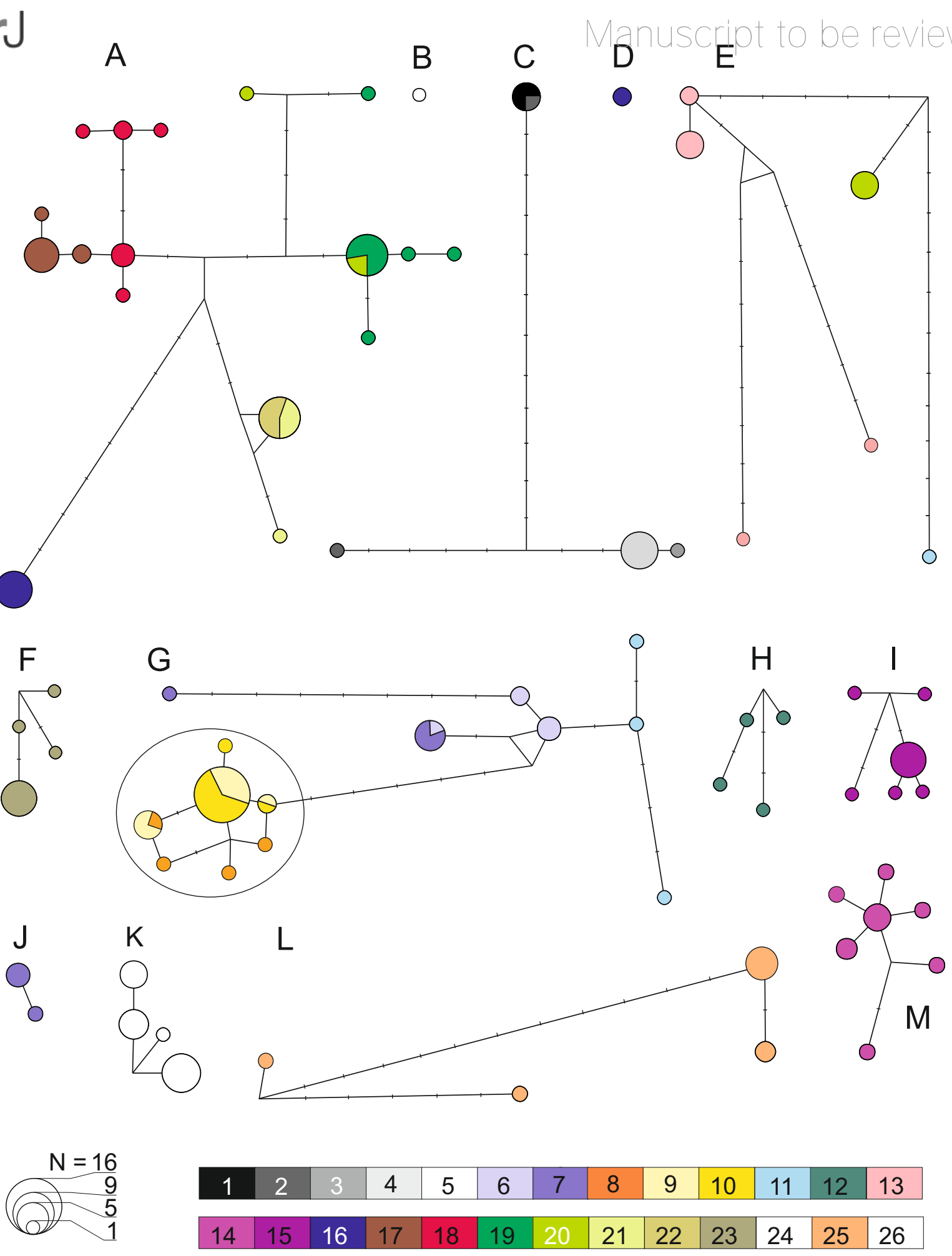

